\title{
Utility of an image-based canopy reflectance modeling tool for remote estimation of LAI and leaf chlorophyll content at regional scales
}

\author{
Rasmus Houborg ${ }^{a}$, Martha C. Anderson ${ }^{b}$ \\ ${ }^{a}$ Earth System Science Interdisciplinary Center, University of Maryland, College Park and \\ Hydrological Sciences Branch, NASA Goddard Space Flight Center, Greenbelt, MD \\ Rasmus.Houborg@nasa.gov \\ ${ }^{\mathrm{b}}$ USDA-ARS Hydrology and Remote Sensing Laboratory, Building 007, BARC-West, 10300 \\ Baltimore Ave, Beltsville, Maryland 20705, USA \\ Martha.Anderson@ars.usda.gov
}

\begin{abstract}
This paper describes a novel physically-based approach for estimating leaf area index (LAI) and leaf chlorophyll content $\left(\mathrm{C}_{\mathrm{ab}}\right)$ at regional scales that relies on radiance data acquirable from a suite of aircraft and operational satellite sensors. The REGularized canopy reFLECtance (REGFLEC) modeling tool integrates leaf optics (PROSPECT), canopy reflectance (ACRM), and atmospheric radiative transfer (6SV1) model components, facilitating the direct use of at-sensor radiances in green, red and near-infrared wavelengths. REGFLEC adopts a multi-step LUT-based inversion approach and incorporates image-based techniques to reduce the confounding effects of land cover specific vegetation parameters and soil reflectance. REGFLEC was applied to agricultural and natural vegetation areas using 10 $\mathrm{m}$ and $20 \mathrm{~m}$ resolution SPOT imagery, and variable environmental and plant development conditions allowed for model validation over a wide range in LAI $(0-6)$ and $\mathrm{C}_{\mathrm{ab}}(20-75 \mu \mathrm{g}$ $\mathrm{cm}^{-2}$ ). Validation against in-situ measurements yielded relative root-mean-square deviations on the order of $13 \%(0.4)$ for LAI and between $\left.11-19 \%(4.9-9.1 \mu \mathrm{g} \mathrm{cm})^{-2}\right)$ for $C_{a b}$. REGFLEC demonstrated good utility in detecting spatial and temporal variations in LAI and $\mathrm{C}_{\mathrm{ab}}$ without requiring site-specific data for calibration. The physical approach presented here can quite easily be applied to other regions and has the potential of being more universally applicable than traditional empirical approaches for retrieving LAI and $\mathrm{C}_{\mathrm{ab}}$.
\end{abstract}

Keywords: Leaf chlorophyll, LAI, radiative transfer, SPOT, Look-up table inversion, Regularization.

\section{INTRODUCTION}

Accurate spatially and temporally distributed information about key biophysical and biochemical variables describing land surface vegetation canopies is of critical value for many ecological, agronomic, and meteorological applications. Leaf area index (LAI), defined as the single sided leaf area per unit horizontal ground area, serves as the key vegetation biophysical determinant for variations in land surface fluxes of energy, water and carbon [14]. Leaf chlorophyll content $\left(\mathrm{C}_{\mathrm{ab}}\right)$, defined as total chlorophyll (chlorophyll $a+$ chlorophyll $b$ ) content on a leaf area basis $\left(\mu \mathrm{g} \mathrm{cm}^{-2}\right)$, is an important indicator of the plant physiological condition. Chlorophylls absorb photosynthetically active radiation and thus function as vital pigments for photosynthesis. Not surprisingly $\mathrm{C}_{\mathrm{ab}}$ is related to leaf nitrogen and photosynthetic capacity of the vegetation $[5,6]$ and it can be used to detect vegetation stress [7-9] and leaf nitrogen deficiency [10-13]. Ref. 14 demonstrated utility in using chlorophyll content for monitoring vegetation productivity, and accurate maps of leaf chlorophyll content would also be valuable in the context of climate change to aid the establishment of reliable regional and global carbon budgets. 
Remote sensing is a cost-effective means for monitoring the terrestrial biosphere and vegetation dynamics at a range of spatial and temporal scales. The success of the remote sensing approach depends on the nature and quality of the radiometric data and on our ability to relate the satellite signal (at-sensor radiance) to characteristics of the land surface vegetation. A critical step is the conversion of at-sensor radiances to surface reflectances by removing the atmospheric effect of gaseous absorption, molecular scattering and aerosols. Accurate atmospheric correction of satellite data is particularly important for physically-based retrieval algorithms that require accurate quantitative reflectance observations as input [15]. While the empirical-statistical approach that links vegetation indices (VI) and vegetation variables using experimental data is less affected by e.g. radiometric calibration accuracy and atmospheric factors, relationships derived using this approach tend to be specific to the study region and the atmospheric and experimental conditions at the time of the satellite acquisition. Nevertheless, the empirical approach has been widely adopted for retrieving vegetation variables [16-19] due to its simplicity and low computational demand. However empirical relationships typically lack generality; there is no unique relationship between a sought vegetation variable and a VI of choice but rather a family of relationships, each a function of canopy characteristics, soil background effects and external conditions (i.e. atmospheric state, view-sun geometry) [20-23].

Radiative transfer models based on physical laws that describe the transfer and interaction of radiation within the atmospheric column and canopy provide an explicit connection between the vegetation biophysical variables and the radiance signal received at the satellite sensor. Physical insight into radiative transfer mechanisms is needed to develop more flexible retrieval schemes that correct for the confounding influence of internal and external factors and assure applicability in diverse geographic locations with widely varying environmental conditions and species compositions. The physical approach has become a promising alternative given the high radiometric quality of current satellite sensors [24], advances in atmospheric radiative transfer modeling [25,26], and enhanced capabilities for describing atmospheric scattering and absorption characteristics in space and time $[27,28]$.

The physically-based retrieval of canopy variables requires the inversion of a CR model. In this process, satellite reflectance observations are matched with simulated reflectance spectra to identify the combination of soil and vegetation variables providing the best reflectance fit. Commonly used inversion strategies include iterative numerical optimization methods [29,30], look-up table approaches [31-33] and artificial neural network methods [3436]. Irrespective of the strategy, the inversion process is ill-posed by nature due to measurements and model uncertainties (i.e. different combinations of model parameters may correspond to almost identical spectra) [31]. The use of a priori knowledge (e.g. canopy type and architecture, model parameter ranges) has been suggested as an efficient way to solve illposed inverse problems $[31,37,38]$, but this 'regularization' technique typically relies on the existence of experimental data collected at the site of interest. Using multiple MODIS images, Ref. 23 demonstrated how the temporal evolution of LAI derived from EVI - LAI relationships could be used to constrain the inverse retrieval of canopy characteristics. Ref. 39 suggested that adjacent pixels belonging to the same crop field contain supplementary spectral information, and he demonstrated that confounding effects between LAI and leaf inclination angle were reduced when incorporating the radiometric information from neighboring pixels during model inversion. Ref. 40 took this a step further and reported good LAI and $\mathrm{C}_{\mathrm{ab}}$ retrieval accuracies using an image-based regularization strategy that assumed spatial and temporal invariance of dry matter content, vegetation clumping and leaf angle distribution within well-defined land cover classes.

Recently Ref. 10 developed the REGularized canopy reFLECtance (REGFLEC) tool that combines atmospheric radiative transfer, canopy reflectance and leaf optics modules for direct image-based retrievals of LAI and $\mathrm{C}_{\mathrm{ab}}$ from at-sensor radiance observations. REGFLEC requires radiometric information from only 3 spectral bands (green, red and near-infrared) 
available on most airborne and satellite-based sensor systems. Since REGFLEC is entirely image-based, it doesn't rely on ground-based data for model calibration, and being physically-based it allows for variations in sensor characteristics, atmospheric absorption and scattering conditions, soil background conditions, surface BRDF and species composition. In principle the tool has utility in diverse geographic locations and at a range of spatial scales. Ref. 10 reported robust REGFLEC retrievals of LAI and $\mathrm{C}_{\mathrm{ab}}$ at the field scale with relative root-mean-square-deviations on the order of $10-17 \%$.

The focus of this study is on the regional-scale applicability of REGFLEC. Important modifications to the retrieval technique are incorporated to make it more suitable for regionalscale applications. These involve: 1) the use of an ancillary land cover map to define classes with spatially uniform canopy characteristics (i.e. leaf structure, Markov clumping, leaf inclination angle, brown pigment concentration of senescent leaf material), which is needed to constrain the retrieval of LAI and $\mathrm{C}_{\mathrm{ab}} ; 2$ ) the use of a soil texture map to assist the regional extrapolation of soil brightness retrieval; 3) Refined techniques for correcting for confounding influences of soil background effects and canopy fraction of senescent leaf material on LAI and $\mathrm{C}_{\mathrm{ab}}$ retrievals; and 4) A novel look-up-table based inversion approach for faster and more reliable parameter retrievals.

Many studies have focused on finding vegetation indices (VI) that maximize the sensitivity to the variable of interest while minimizing the sensitivity to other internal and external variables [20,41-43]. However, the translation of spectral reflectance data into a VI tends to reduce the sensitivity to the variable of interest. For instance, the widely used Normalized Difference Vegetation Index (NDVI), which combines reflectance in the nearinfrared and red wavebands, approaches a saturation level at intermediate values of LAI whereas near-infrared reflectances remain sensitive to LAI in densely vegetated areas [23,44]. Likewise, VIs that combine reflectances from the near-infrared and peak leaf chlorophyll sensitive green $(540-560 \mathrm{~nm})$ or red-edge $(700-730 \mathrm{~nm})$ parts of the spectrum [45] are typically not correlated with leaf chlorophyll content due to a high variability of near-infrared reflectances relative to chlorophyll sensitive reflectance data [5]. In REGFLEC, reflectances from the near-infrared waveband are incorporated as direct predictors of LAI and the mapping of leaf chlorophyll is facilitated using reflectances from the green waveband.

The atmospheric radiative transfer (6SV1) and canopy reflectance (ACRM-PROSPECT) model components of REGFLEC will be briefly described in the next section followed by a detailed description of REGFLEC soil background correction (section 3.1), land-cover specific parameter retrieval (section 3.2) and pixel-wise LAI and $\mathrm{C}_{\mathrm{ab}}$ retrieval (section 3.3) modules. REGFLEC is applied to study regions in Maryland and Oklahoma using 10 and 20 $\mathrm{m}$ resolution SPOT satellite data, respectively. Estimates of LAI and $\mathrm{C}_{\mathrm{ab}}$ are validated using ground data collected within fields of corn, wheat, soybean, cotton, alfalfa, grass and peanuts.

\section{RADIATIVE TRANSFER MODELS}

The atmospheric radiative transfer (6SV1) and canopy reflectance (ACRM) models were described in detail in Ref. 10 and only a brief overview will be given here.

\section{$2.16 \mathrm{SV} 1$}

The vector version of the 6S (Second Simulation of the Satellite Signal in the Solar Spectrum) atmospheric radiative transfer model [46,47] converts at-sensor radiance to directional surface reflectance. $6 \mathrm{SV} 1$ is an advanced radiative transfer code designed to simulate the reflection of solar radiation by a coupled atmosphere-surface system for a wide range of atmospheric, spectral and geometrical conditions. For the present application, input parameters include sun zenith $\left(\theta_{\mathrm{s}}\right)$, view zenith $\left(\theta_{\mathrm{v}}\right)$, and relative azimuth $\left(\theta_{\mathrm{raz}}\right)$ angles, total ozone content $\left(\mathrm{O}_{3}\right)$, aerosol optical depth at $550 \mathrm{~nm}\left(\tau_{550}\right)$, total precipitable water $(\mathrm{TPW})$, and type of aerosol model $\left(\tau_{\text {type }}\right)$. The type of aerosol model (Continental, Urban, Maritime and Desert) 
a)

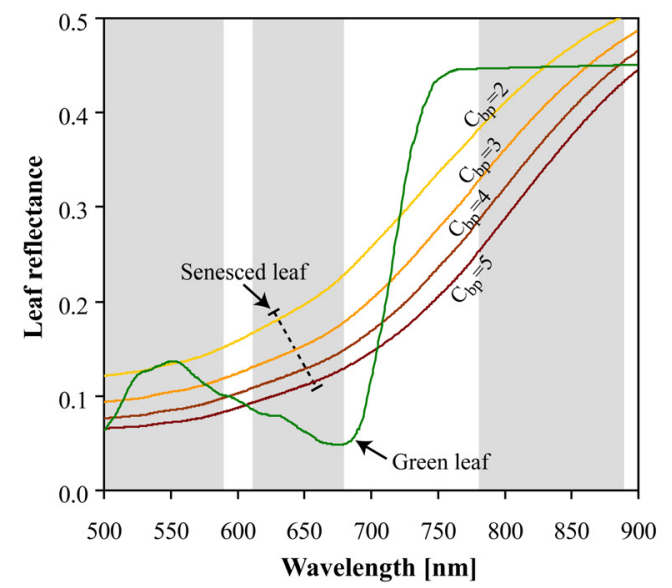

b)

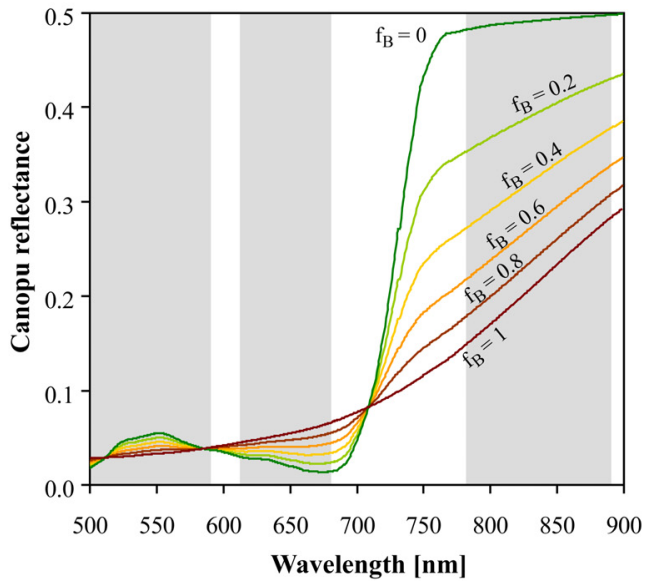

Fig. 1. a) PROSPECT simulations of leaf reflectance spectra for green and senescent (no green pigments presents) leaf material. The brown pigment concentration $\left(\mathrm{C}_{\mathrm{bp}}\right)$ controls the color (i.e. yellow - brown) of the senescent leaf material. The green

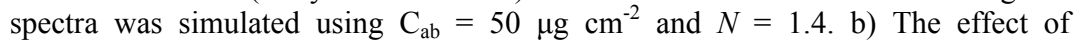
variations in the canopy fraction of senescent leaf material $\left(\mathrm{f}_{\mathrm{B}}\right)$ on canopy reflectance spectra for a hypothetical canopy ( $\mathrm{LAI}=4, \mathrm{C}_{\mathrm{ab}}=50, N=1.4, S_{z}=1, \theta_{l}=55$, $\mathrm{C}_{\mathrm{bp}}=3, \mathrm{~s}_{1}=0.25, \theta_{\mathrm{s}}=25, \theta_{\mathrm{v}}=15, \theta_{\mathrm{raz}}=140$ ). The gray sections denote the bandwidths of the green, red and near-infrared band of the SPOT sensor (section 5.1).

determines the aerosol volume and size distributions, and an option is implemented to allow mixing of aerosol models. The ground BRDF, required to determine the directional effect of the target, is computed in 6SV1 following the Markov chain canopy reflectance model, ACRM [48,49] (section 2.2). The consideration of directional effects is believed to be important due to significant non-Lambertian scattering properties of vegetation surfaces [50] and the directional influence of many model parameters on the canopy reflectance [51].

\subsection{ACRM}

The turbid medium Markov chain canopy reflectance model, ACRM [48,49] incorporates Markov properties of stand geometry and has demonstrated utility in a range of managed and natural vegetation canopies $[23,35,40,52]$. The model operates in the spectral domain 400 $2500 \mathrm{~nm}$ and calculates directional canopy reflectance at a spectral resolution of $1 \mathrm{~nm}$. The ACRM used here is a modified version that incorporates the mean leaf inclination angle $\left(\theta_{l}\right)$ and canopy fraction of senescent leaf material $\left(f_{B}\right)$ (see Ref. 10 for complete details). Additional canopy input parameters include total leaf area index (LAI), Markov clumping parameter $\left(S_{Z}\right)$ and hot spot parameter $\left(\mathrm{S}_{\mathrm{L}}\right)$. The model accounts for non-lambertian soil reflectance and soil reflectance spectra are here approximated as a function of a single soil parameter $\left(\mathrm{s}_{1}\right)[10]$.

In ACRM, the spectra of leaf reflectance and transmittance are computed using the most recent version of the leaf optics model PROSPECT [53,54]. In this five-variable PROSPECT model, leaf scattering is described by the leaf mesophyll structure parameter $N$ (the effective number of elementary layers inside a leaf) and a tabulated wavelength-dependent refractive index of the leaf surface wax. The calculation of leaf absorption depends on the chlorophyll $a$ and $b$ content $\left(\mathrm{C}_{\mathrm{ab}}\right)$, the equivalent water thickness $\left(\mathrm{C}_{\mathrm{w}}\right)$, the dry matter content $\left(\mathrm{C}_{\mathrm{m}}\right)$, and leaf brown pigment $\left(\mathrm{C}_{\mathrm{bp}}\right)$. The setting of $\mathrm{C}_{\mathrm{w}}$ is not important since leaf water has no effect on the reflectance in the visible and near-infrared wavebands [23]. The effect of $\mathrm{C}_{\mathrm{m}}$ is predominantly 


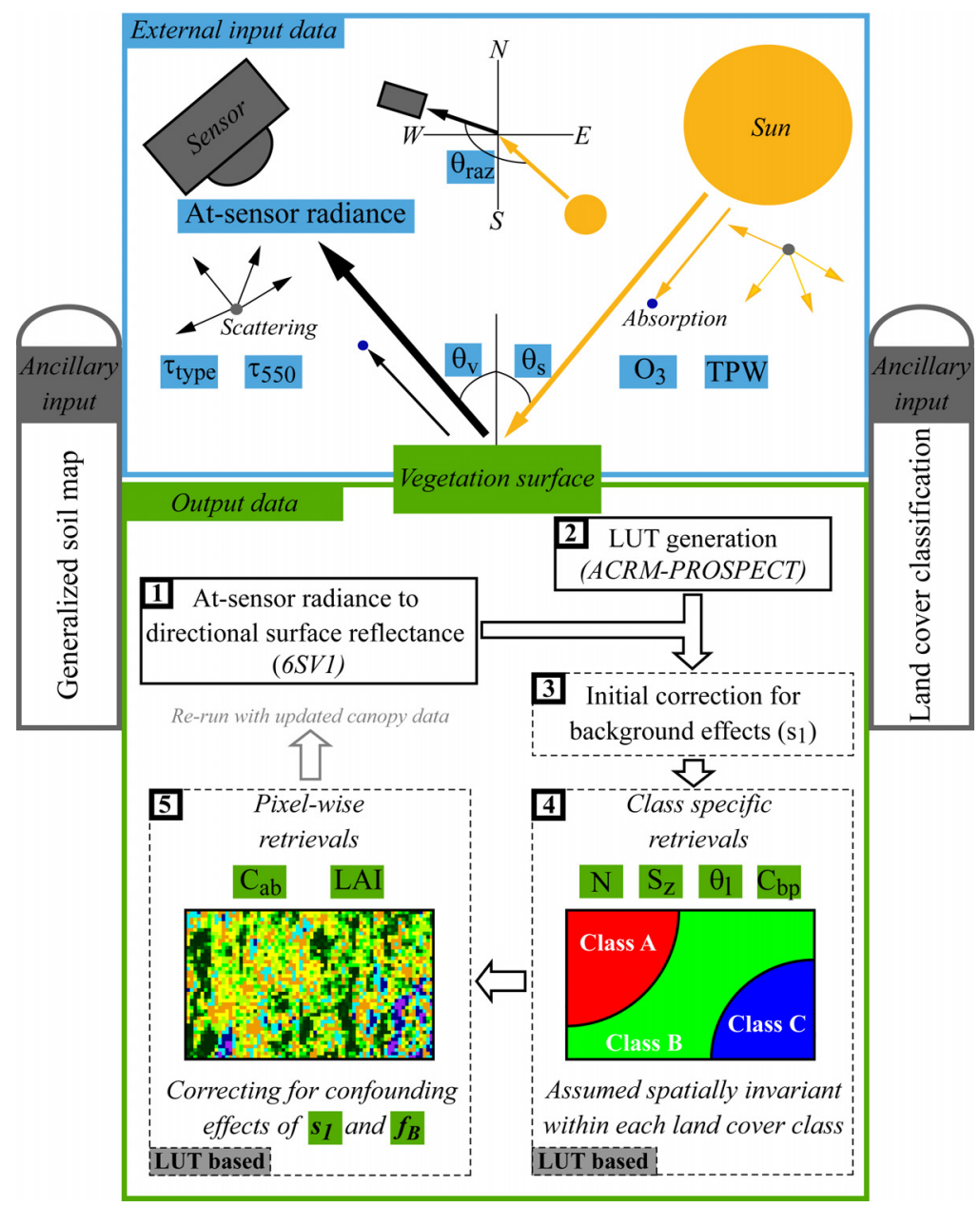

Fig. 2. Schematic diagram of the regional-scale version of the coupled 6SV1 ACRM - PROSPECT regularized parameter retrieval tool (REGFLEC). Parameter descriptions are given in the text.

in wavelengths longer than $1200 \mathrm{~nm}$ [23,55], and is set to fixed values of 50 and $150 \mathrm{~g} \mathrm{~m}^{-2}$ for cropland [56] and forest [57], respectively.

Brown pigments appear when leaves senesce and represent light absorption by nonchlorophyll pigments. $\mathrm{C}_{\mathrm{bp}}$ may vary between 0 (no light absorption) and $\sim 5$ (max. light absorption). In this model setup, green and senescent leaf material is assumed to be dissociated and green leaves assigned a fixed $C_{b p}$ value of 0 . The leaf mesophyll structure and leaf chlorophyll content of senescent leaf material is fixed to 2.5 and $0 \mu \mathrm{g} \mathrm{cm}^{-2}$, respectively. Fig. 1a illustrates PROSPECT simulations of leaf reflectance spectra for green and senescent (no green pigments presents) leaf material. Evidently the value used for $\mathrm{C}_{\mathrm{bp}}$ that controls the color (i.e. yellow - brown) of the senescent leaf material has a significant impact on the leaf reflectance spectra. Canopy reflectance spectra representative of intermixed green and senescent leaf material are simulated by weighing PROSPECT leaf reflectance and transmittance spectra for green $\left(C_{b p}=0\right)$ and senescent leaf material $\left(C_{b p}=2-5\right)$ with the canopy fraction of senescent leaves $\left(f_{B}\right)$. The effect of variations in $f_{B}$ on canopy reflectance spectra is shown for a hypothetical canopy in Fig. 1b, which demonstrates a significant effect 
in the near-infrared region and on the green $(\sim 550 \mathrm{~nm})$ and red $(\sim 650 \mathrm{~nm})$ band reflectance difference.

\section{REGFLEC}

The regional scale version of the REGularized canopy reFLECtance (REGFLEC) modeling tool (Fig. 2) adopts the general principles put forward in Ref. 10 but includes important modifications required for regional applicability of the scheme. REGFLEC integrates the atmospheric radiative transfer (section 2.1) and leaf optics and canopy reflectance (section 2.2) models and adopts a look-up table based inversion technique for the retrieval of key biophysical properties (LAI and $\mathrm{C}_{\mathrm{ab}}$ ). Input parameters to the model include remotely sensed at-sensor radiance observations in green, red, and near-infrared wavelengths, atmospheric state parameters to describe atmospheric scattering and absorption characteristics, and solar and sensor view angle geometries (Fig. 2).

The REGFLEC retrieval scheme is here described as a 5-step procedure as displayed in Fig. 2. The two first steps follow strictly the procedure described in Ref. 10. As a brief summary, the first step in REGFLEC involves the conversion of at-sensor radiances in green, red and near-infrared wavebands to directional surface reflectance using the 6SV1 radiative transfer model (section 2.1). In step 2, model generated curves of LAI as a function of nearinfrared reflectance $\left(\rho_{\text {nir }}\right)$, Normalized Difference Vegetation Index (NDVI), and Green Normalized Difference Vegetation Index (GNDVI), in addition to curves of leaf chlorophyll content as a function of green reflectance ( $\left.\rho_{\text {green }}\right)$ are stored in Look-up tables (LUTs) for later access. The LUTs are generated by running ACRM (section 2.2) in forward mode using a wide parameter distribution space [10]. The three remaining steps involve important modifications and are explained in detail in three separate sections below.

\subsection{Initial soil background correction (step 3)}

The correction for background effects is separated from the estimation of canopy parameters to constrain the retrieval process and to minimize the possibly confounding influence of the background reflectance signal.

Single band (e.g. LAI $-\rho_{\text {nir }}$ ) and vegetation index (e.g. LAI - NDVI) relationships differ distinctly in their response to variations in soil reflectance (i.e. $s_{1}$ parameter) [10]. The strong sensitivity of LAI $-\rho_{\text {nir }}$ relationships to variations in $\mathrm{s}_{1}$, even for fairly dense vegetation, is a result of high canopy penetration capabilities of $\rho_{\text {nir }}$, whereas the significantly reduced sensitivity of LAI - NDVI and LAI - GNDVI relationships to soil background effects is due to the VI normalization. At low vegetation coverage, a mismatch in LAI estimated using observations of $\rho_{\text {nir }}\left(\right.$ LAI $-\rho_{\text {nir }}$ ), NDVI (LAI - NDVI), and GNDVI (LAI - GNDVI), respectively, is most likely due to erroneous soil reflectance $\left(\mathrm{s}_{1}\right)$ values, as these relationships are only minimally influenced by canopy characteristics (when the vegetation amount is low).

This phenomena is exploited in REGFLEC by 1) accessing pre-computed spectral reflectance relationships (LUT database) using default vegetation parameters settings [10], 2) generating maps of LAI as a function of observed $\rho_{\text {nir }}$, NDVI and GNDVI over a wide range in $\mathrm{s}_{1}(0.05-0.5)$, and 3$)$ on a pixel-wise basis, retaining the $\mathrm{s}_{1}$ value that produces the best agreement between the three separate LAI estimates (i.e. LAI $f\left(\rho_{\text {nir }}\right) \sim \mathrm{LAI}=f(\mathrm{NDVI}) \sim$ $\mathrm{LAI}=f(\mathrm{GNDVI}))$. As the technique is only meaningful for low vegetation coverage, $\mathrm{s}_{1}$ retrievals are only retained for pixels where the derived LAI is less than 0.5 .

The extrapolation of the $s_{1}$ retrievals to vegetated pixels (i.e. LAI $>0.5$ ) is based on the assumption that soil texture (i.e. \% sand, silt, clay, humus content) is the key determinant for spatial variations in soil reflectance. Thus valid retrievals of $\mathrm{s}_{1}$ are averaged for each soil type within the region, as determined from an ancillary soil texture map (Fig. 2), and the soil type specific values extrapolated to the unfilled vegetated pixels using the soil texture map. The soil brightness of individual pixels is also affected by soil moisture conditions. A wet soil is 

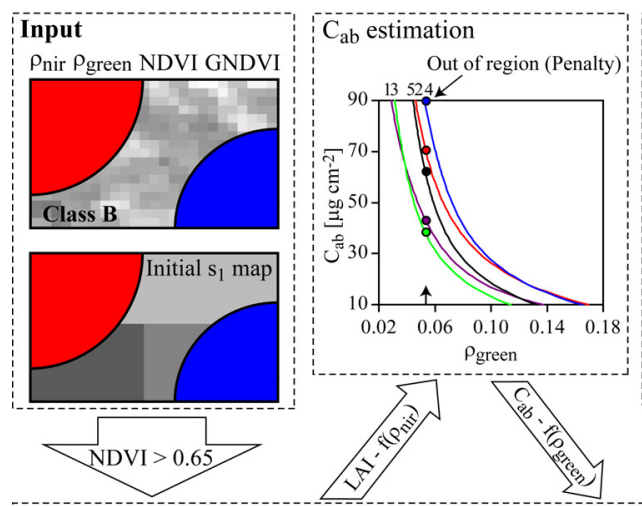

Retrieve best-fit class specific parameters

Calculate $\triangle$ LAI for each parameter combination (illustrated for one pixel)

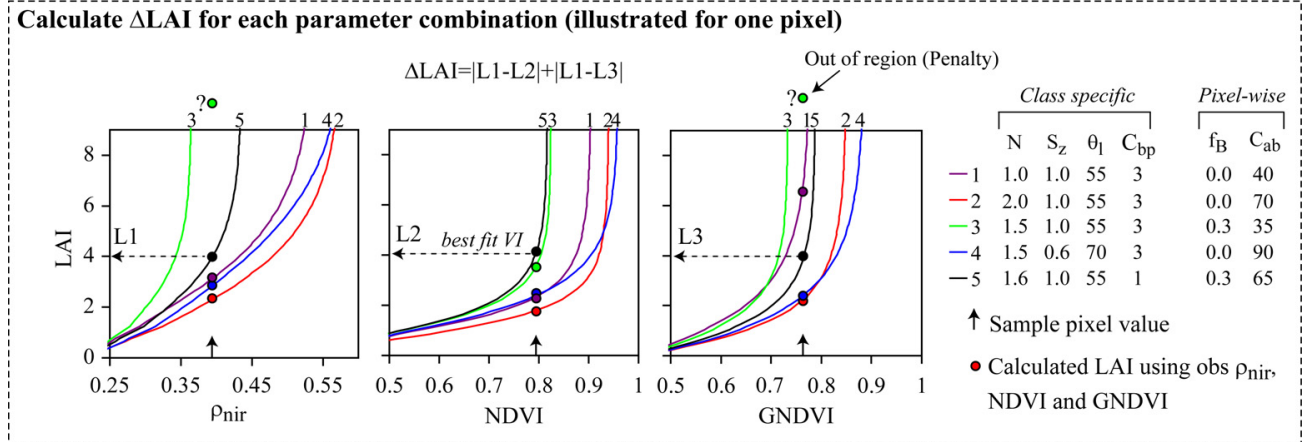

LUT database
LAI - $\rho_{\text {nir }}, \mathrm{C}_{\mathrm{ab}}-\rho_{\text {green }}, \mathrm{LAI}$ - NDVI, LAI - GNDVI

Fig. 3. Schematic diagram of the procedure adopted for retrieving canopy parameters (i.e. $N, S_{z}, C_{b p}, \theta_{l}$ ) assumed constant within a given land cover class. The basis idea is to use satellite observations of near-infrared reflectance, NDVI and GNDVI to calculate three separate LAI values for each pixel (using the precomputed LUT database) and then to find the set of parameters (5 sample combinations illustrated here) that produces the lowest absolute difference between these LAI estimates. See section 3.2 for a detailed description.

much darker than a dry soil and the value of $\mathrm{s}_{1}$ will decrease with an increase in the soil moisture content. In an attempt to incorporate this factor into the extrapolation procedure, the average of $s_{1}$ retrieved for each soil type and subsequent extrapolations is computed within sub-regions $(2 \mathrm{~km} \times 2 \mathrm{~km}$ quadrants $)$ where spatial variations in soil moisture conditions within a given soil texture class are expected to be less pronounced.

This extrapolation approach provides a first crude estimate of spatially distributed soil reflectance values (i.e. $s_{1}$ ) for the vegetated areas. In the $5^{\text {th }}$ stage of REGFLEC (Fig. 2), a pixel-wise refinement of $s_{1}$ is implemented (section 3.3).

\subsection{Land cover specific parameter retrievals (step 4)}

A schematic diagram of the land cover specific parameter retrieval procedure is given in Fig. 3. Leaf structure $(N)$, Markov clumping parameter $\left(S_{z}\right)$, leaf inclination angle $\left(\theta_{l}\right)$, and brown pigment concentration $\left(C_{b p}\right)$ are here denoted as land cover specific parameters (i.e. assumed to remain constant within a given land cover class). This assumption is believed to constrain the inverse retrieval of LAI and $\mathrm{C}_{\mathrm{ab}}$ from the directional spectral reflectance signal as it allows the radiometric information of pixels belonging to the same land cover class to be simultaneously incorporated in the inversion $[10,39]$. 
The retrieval procedure follows the general principle described in section 3.1 in that observations of $\rho_{\text {nir }}$, NDVI and GNDVI are used to calculate separate LAI maps for a wide parameter distribution space (for a large number of class-specific parameter combinations) using relationships from the LUT database (Fig. 3). The selection of optimal values for $N, S_{z}$, $\theta_{l}$ and $C_{b p}$ is guided by minimizing the LAI difference ( $\left.\Delta \mathrm{LAI}\right)$ calculated for each pixel according to the relationship

$$
\Delta L A I_{i}=\left|L 1_{i}-L 2_{i}\right|+\left|L 1_{i}-L 3_{i}\right|,
$$

where $\mathrm{L} 1_{\mathrm{i}}, \mathrm{L} 2_{\mathrm{i}}$ and $\mathrm{L} 3_{\mathrm{i}}$ are $\mathrm{LAI}$ values estimated as a function of $\rho_{\text {nir }}$, NDVI and GNDVI, respectively using LUT relationships for each parameter combination $(i)$ of $N(1.0,1.2$.. 2.0), $S_{z}\left(0.5,0.6\right.$.. 1.0), $\theta_{l}(40,55,70)$, and $C_{b p}(2,3 . .5)$.

$\triangle \mathrm{LAI}$ is only calculated for pixels with intermediate to high vegetation coverage, as determined by an NDVI threshold of 0.65 (Fig. 3). This maximizes the sensitivity of the reflectance signal to the land cover specific leaf and canopy variables whereas the influence of the potentially confounding background reflectance signal is reduced. As the consideration of pixel-wise variability in soil reflectance (i.e. $s_{1}$ ) is less imperative at this stage in the modeling process, soil-type averaged $s_{1}$ values (see section 3.1 ) are used as input for accessing the appropriate LUT relationships.

Fig. 3 illustrates the variation of LAI - $\rho_{\text {nir, }}$ LAI - NDVI and LAI - GNDVI relationships for 5 sample parameter combinations. Note that the leaf chlorophyll value $\left(\mathrm{C}_{\mathrm{ab}}\right)$, required for the $\mathrm{C}_{\mathrm{ab}}$ dependent NDVI and GNDVI relationships, is generated for each land cover specific parameter combination using $\mathrm{C}_{\mathrm{ab}}-\rho_{\text {green }}$ relationships from the LUT database (Fig. 3). Evidently the choice of parameter setting has a significant impact on the relationships. Calculated LAI values (for the sample pixel value) are seen to vary from 2 to $>9$ and the divergence $(\triangle \mathrm{LAI})$ between the three independent LAI estimates varies considerably.

In principle, the optimal parameter combination (i.e. $N, S_{z}, \theta_{l}, C_{b p}$ ) will produce the closest match between the three LAI estimates for each pixel. However due to the ill-posed nature of model inversion [10] different parameter settings may yield identical reflectance spectra and more than one parameter combination may result in matching LAI values. Additional constraints are therefore introduced by creating so-called penalty maps for each parameter combination (Fig. 3). Penalties are assigned on a pixel-wise basis if 1) the upper (9.0) or lower (0.01) LAI bound is reached by any of the three LAI estimates, 2) $\mathrm{C}_{\mathrm{ab}}$ values generated by $C_{a b}-\rho_{\text {green }}$ relationships encounter out of range conditions (i.e. $10>C_{a b}>90 \mu \mathrm{g} \mathrm{cm}^{-2}$ ), and 3) neighboring pixels (i.e. $3 \times 3$ pixel box) encounter out of range $L A I$ or $C_{a b}$ values at a given canopy fraction of senescent material $\left(f_{B}\right)$. While $f_{B}$ is allowed to vary between pixels within a given land cover class, this latter condition assumes that $f_{B}$ values are fairly similar among neighboring pixels.

For each parameter combination, the $\Delta \mathrm{LAI}$ and penalty maps are added together and then averaged spatially to produce a single indicator value. The parameter combination that results in the lowest indicator value is then retained and assumed to apply for the specific land cover class. In this process a land cover averaged $\mathrm{f}_{\mathrm{B}}$ is also output along with the standard deviation of $f_{B}$ within that class.

\subsection{Pixel-wise retrievals of LAI and $\mathrm{C}_{\mathrm{ab}}($ step 5)}

With the land cover-specific determination of $N, S_{z}, \theta_{l}$, and $C_{b p}$ completed, LAI and $\mathrm{C}_{\mathrm{ab}}$ can be estimated for all pixels within each land cover class using relationships from the LUT database. Since $N, S_{z}, \theta_{l}$, and $C_{b p}$ are now fixed, the LAI - $\rho_{n i r}$ LUT is reduced to a multidimensional array of only 2 dependent variables $\left(f_{B}\right.$ and $\left.\mathrm{s}_{1}\right)$ while the $\mathrm{C}_{\mathrm{ab}}-\rho_{\text {green }}$, LAI NDVI, and LAI - GNDVI LUTs are reduced to 3 dimensional arrays $\left(\mathrm{C}_{\mathrm{ab}}\right.$ or LAI, $f_{B}$ and $\mathrm{s}_{1}$ being the dependent variables). 


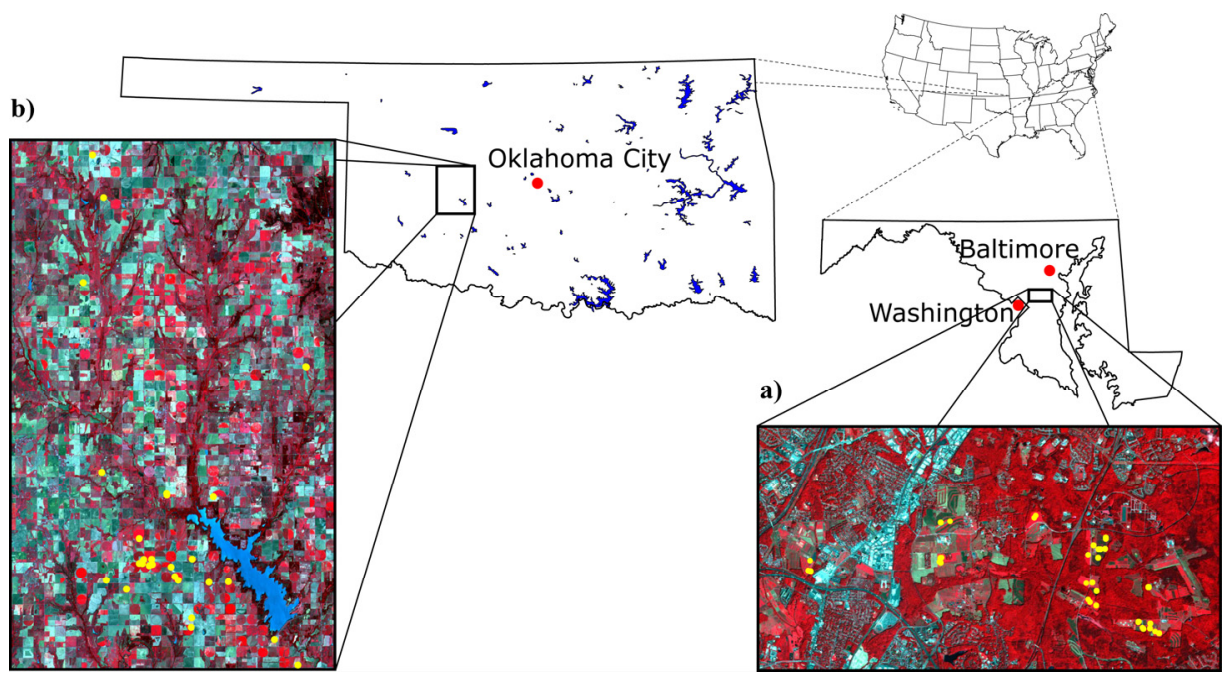

Fig. 4. Geographic location of the USDA-ARS Beltsville Agricultural Research Center (BARC) (a) and Fort Cobb (FC) (b) study areas. The yellow dots indicate LAI and leaf chlorophyll in-situ sampling sites.

The approach adopted here aims at correcting for the confounding influence that variation in $\mathrm{s}_{1}$ and $\mathrm{f}_{\mathrm{B}}$ may have on the LAI and $\mathrm{C}_{\mathrm{ab}}$ retrievals. This is facilitated by iteratively adjusting $f_{B}$ and $s_{1}$ to provide a match between LAI values generated as a function of observed $\rho_{\text {nir }}$, NDVI and GNDVI, respectively. The allowed range of $f_{B}$ variation is determined by the land cover-specific average and standard deviation $\mathrm{f}_{\mathrm{B}}$ (section 3.2) whereas $\mathrm{s}_{1}$ is allowed to vary with \pm 0.05 from the initial values (section 3.1). The optimal set of $f_{B}$ and $s_{1}$ is determined for each pixel and the corresponding LAI - $\rho_{\text {nir }} / \mathrm{LAI}$ - NDVI and $\mathrm{C}_{\mathrm{ab}}-\rho_{\text {green }}$ relationships are used for mapping LAI and $\mathrm{C}_{\mathrm{ab}}$ over the modeling domain. For the output LAI map, LAI - $\rho_{\text {nir }}$ relationships are preferred over LAI - NDVI relationships at intermediate to high vegetation densities as the NDVI signal begins to saturate at intermediate densities whereas $\rho_{\text {nir }}$ remains responsive to changing leaf biomass up to LAI $\sim 6$ [10]. In contrast, LAI - NDVI relationships are preferred for low vegetation coverage due to reduced sensitivity to background effects (compared to $\rho_{\text {nir }}$ ).

\section{FIELD EXPERIMENTS}

Satellite and ground-based data were collected in 2007 at the USDA-ARS Beltsville Agricultural Research Center (BARC), Maryland $\left(39.02^{\circ} \mathrm{N}, 76.85^{\circ} \mathrm{W}\right)$ during two intensive weeklong field campaigns and at Fort Cobb (FC), Oklahoma (35.10 N, $\left.98.44^{\circ} \mathrm{W}\right)$ during the Cloud and Land Surface Interaction Campaign (CLASIC).

The BARC study area (Fig. 4a) includes the city of Beltsville and is characterized by a mix of forest (primarily deciduous broad-leaf species such as maple, oak and beech) and small fields of non-irrigated farmland (primarily corn, soybean and winter wheat). The region has a flat topography and sandy to loamy soils. It is located in the humid subtropical climate zone with usually hot and humid summers and an annual rainfall of around $1000 \mathrm{~mm}$. The 2007 growing season was characterized by precipitation totals well below average from around mid-June, and at the time of the first satellite acquisition (DOY 208) many fields were characterized by a high degree of plant stress. At this time winter wheat fields were harvested with stubble, soybeans were maturing and corn fields were in an advanced stage of leaf maturity with beginning leaf senescence in many parts. The second satellite acquisition occurred a month later (DOY 239) where the landscape was dominated with generally mature 
fields of soybean, corn fields in an advanced stage of leaf senescence and patches of dense green grass for forage.

The Fort Cobb (FC) study area (Fig. 4b) is located in the Southern Great Plains at an elevation of $\sim 380 \mathrm{~m}$ and is home to significant irrigated wheat farm operations. Secondary crops include corn, peanuts, soybean and cotton. The area lies in a temperate, sub-humid climate and receives about $800 \mathrm{~mm}$ of rain annually. While summers are generally very hot and see moderate amounts of rainfall, the 2007 CLASIC experiment (April - August) was impacted by an extreme weather pattern that caused a record monthly June rainfall, in excess of $300 \mathrm{~mm}$. Mature winter wheat fields dominated the landscape during the first image acquisition (DOY 112). At the time of the second acquisition (DOY 221) weather conditions had finally improved exposing a landscape with fields of corn in a wide range of plant development stages and generally mature fields of cotton, soybean and grass for forage.

\subsection{Biophysical measurements}

Measurements of LAI and leaf chlorophyll were collected within 5 days of each satellite acquisition. The data were collected in plots of $\sim 15 \mathrm{~m} \mathrm{x} 15 \mathrm{~m}$ and $\sim 25 \mathrm{~m} \times 25 \mathrm{~m}$, respectively to provide representative values for comparison with the satellite data. The center in each plot was geolocated using handheld Global Positioning System (GPS) units (accuracy $\approx 4 \mathrm{~m}$ ). LAI was measured non-destructively using a LAI-2000 instrument (LiCor, USA). The LAI measurements were made shortly after sunrise, shortly before sunset or during overcast conditions using a 90 degree mask to prevent interference caused by the operator's presence. For the row crops (i.e. corn, cotton), four readings were made along diagonal transects between the rows as suggested in the LAI-2000 manual for row crops, and repeated once ( 8 below canopy readings in total). We have found that this measurement protocol results in LAI values that are in good agreement with the 'true' LAI (i.e. from destructive leaf sampling).

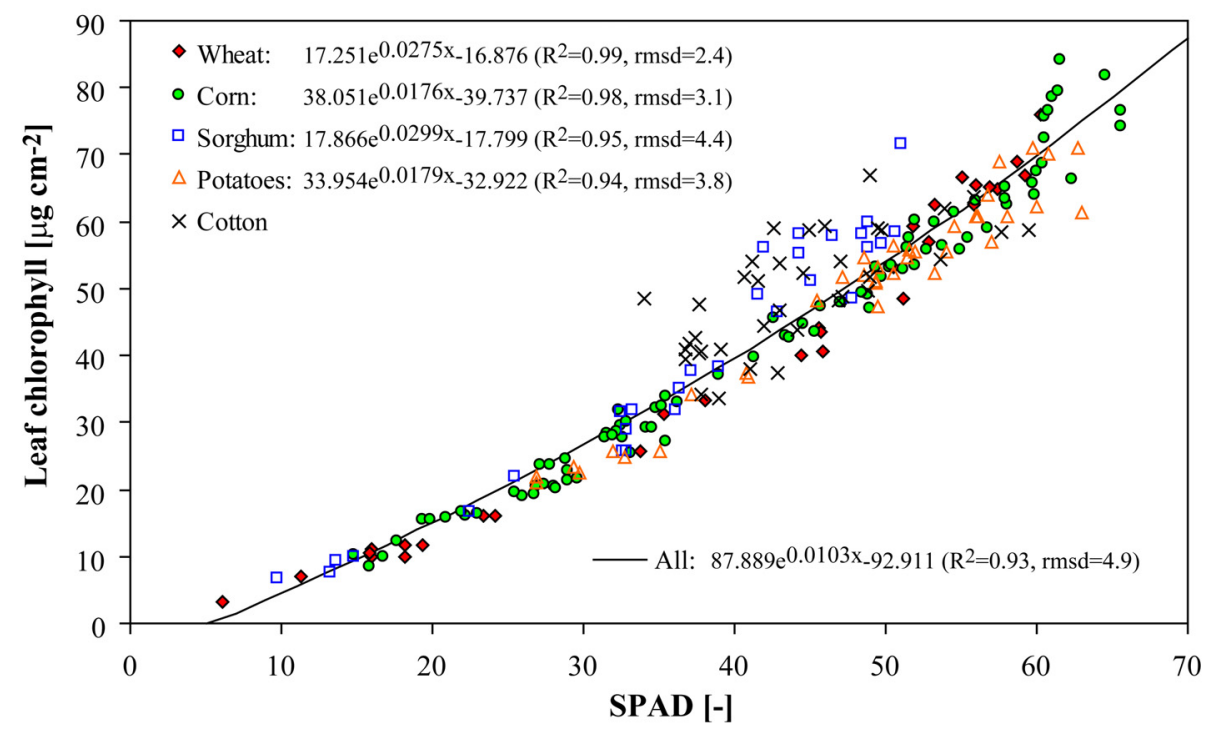

Fig. 5. Species-specific calibration curves used to convert non-dimensional SPAD values to absolute leaf chlorophyll units $\left(\mu \mathrm{g} \mathrm{cm}^{-2}\right)$. The relationships are based on a spectrophotometrical analysis of leaf samples using DMSO as extraction solvent (see section 4.1). The exponential model fits are provided for wheat, corn, sorghum and potato cultivars. The correlation of determination $\left(\mathrm{r}^{2}\right)$ and root-mean-square deviation (rmsd) is listed for each fit. 
The LAI of each plot was calculated as the average of 6 - 10 spatially representative measurements (6-10 x 8 readings).

Leaf chlorophyll content was measured non-destructively with a portable SPAD-502 Chlorophyll meter (Spectrum Technologies, Inc.). This instrument measures leaf transmittance at two wavelengths: red $(650 \mathrm{~nm})$ where light absorbance by chlorophyll is efficient and near-infrared $(940 \mathrm{~nm})$ where absorbance by chlorophyll is insignificant. The SPAD-502 meter calculates a non-dimensional SPAD value $(0-99)$ with a claimed accuracy of \pm 1 SPAD unit. Six separate measurements with the SPAD meter were made on each leaf to assess the variability in chlorophyll content across the leaf. In each of the field plots, the average of $\sim 50 \times 6$ SPAD readings were acquired. During the measurements the sensor head was shaded to avoid direct sunlight from reaching the instrument. In stands with a mix of green and senescent leaves, only the green leaves were measured.

In order to convert the unitless SPAD values into absolute measures of leaf chlorophyll, a relationship between leaf chlorophyll content and SPAD values must be determined. The relationships adopted here are based on a spectrophotometrical analysis of leaf samples collected during the 2008 growing season in Bushland, Texas. The analysis was done using the same SPAD meter that was used during the BARC and Fort Cobb field experiments. Leaf samples were collected from several fields of corn, wheat, cotton, potato and sorghum and transported in a cooler to the lab where the samples were processed immediately. For each leaf sample the mean of 10 SPAD readings was recorded. Two discs (1 cm in diameter) from each leaf sample were then incubated with $4 \mathrm{ml}$ DMSO (Dimethyl sulfoxide) $(99.7 \%)$ and placed in a dark chamber at room temperature for 48 hours (at this time the tissue had certainly become colorless). The absorbance at 648.2 and $664.9 \mathrm{~nm}$ was measured with a SPEC-20 spectrophotometer and total leaf chlorophyll $\left(\mu \mathrm{g} \mathrm{ml}^{-1}\right)$ calculated using the equations listed in Ref. 58. Conversion to the preferred units of $\mu \mathrm{g} \mathrm{cm}^{-2}$ was accomplished by multiplying by the ratio of solvent volume $(\mathrm{ml})$ to the total one-sided area of the leaf disks $\left(\mathrm{cm}^{2}\right)$.

The resultant calibration curves are depicted in Fig. 5. An exponential model provided the best fit to the data, consistent with other studies that have reported deviations from linearity in the high and low SPAD range [59-61]. The correlation between SPAD and $\mathrm{C}_{\mathrm{ab}}$ values are excellent for the wheat, corn, sorghum and potato samples with coefficient of variations $\left(\mathrm{R}^{2}\right)$ ranging from $0.94-0.99$ and root-mean-square (RMS) deviations less than $4.4 \mu \mathrm{g} \mathrm{cm}^{-2}$. Given the narrow range in SPAD values obtained in cotton, a relationship was not fitted to the cotton data. A larger scatter is evident for the cotton dataset, which may be related to the fact that cotton leaves have many veins. Sorghum appears to be characterized by a steeper exponential rise in leaf chlorophyll versus SPAD values. In general, however, the relationship between leaf chlorophyll and SPAD value was reasonably well defined, especially for low to intermediate SPAD values. An exponential fit to the entire dataset (corn, wheat, sorghum, potato, cotton) yielded an $\mathrm{R}^{2}$ of 0.93 and a RMS deviation of $4.9 \mu \mathrm{g} \mathrm{cm}^{-2}$ (Fig. 5). These results indicate in accordance with other studies [59] showing that the determination of leaf chlorophyll per unit area appears to be relatively independent of species.

\section{MODEL INPUT DATA}

\subsection{At-sensor radiance data}

Radiance data in the green $(500-590 \mathrm{~nm})$, red $(610-680 \mathrm{~nm})$ and near-infrared $(780-890 \mathrm{~nm})$ wavebands were acquired by SPOT-5 High Resolution Geometric (HRG-2) and SPOT-4 High Resolution Visible and InfraRed (HRVIR) imaging instruments over the BARC and FC study areas, respectively. The SPOT-5 radiances at the BARC study area were obtained at 10 m resolution at approximately 12:15 p.m. local time for $30 \mathrm{~km} \times 30 \mathrm{~km}$ image swaths. The 
Table 1. Atmospheric state characteristics and view-sun angle geometries for satellite acquisitions at Maryland (BARC) and Oklahoma (Fort Cobb) study sites during 2007.

\begin{tabular}{|c|c|c|c|c|c|c|c|c|c|}
\hline \multirow{2}{*}{$\begin{array}{c}\text { External } \\
\text { parameter }\end{array}$} & \multicolumn{4}{|c|}{ BARC - MD } & \multicolumn{5}{|c|}{ Fort Cobb - OK } \\
\hline & \multicolumn{2}{|c|}{ July $27^{\text {th }}$} & \multicolumn{2}{|c|}{ August $27^{\text {th }}$} & \multicolumn{2}{|c|}{ April $22^{\text {nd }}$} & \multicolumn{3}{|c|}{ August $9^{\text {th }}$} \\
\hline \multirow{2}{*}{$\tau_{550}$} & \multirow{2}{*}{ AERO } & MYD & AERO & MOD & AERO & MYD & \multicolumn{2}{|c|}{ AERO } & MOD \\
\hline & & 0.30 & 0.19 & 0.15 & - & 0.01 & 0.1 & & 0.05 \\
\hline \multirow{2}{*}{ TPW $\left[\mathrm{g} \mathrm{cm}^{-2}\right]$} & AERO & AIRS & AERO & AIRS & AERO & AIRS & \multicolumn{2}{|c|}{ AERO } & AIRS \\
\hline & 3.42 & 3.71 & 2.56 & 2.55 & - & 1.19 & 3.0 & \multicolumn{2}{|c|}{3.21} \\
\hline \multirow{2}{*}{$\mathrm{O}_{3} \quad[\mathrm{~cm}-\mathrm{atm}]$} & \multirow{2}{*}{\multicolumn{2}{|c|}{$\begin{array}{l}\text { AIRS } \\
0.378\end{array}$}} & \multirow{2}{*}{\multicolumn{2}{|c|}{$\begin{array}{l}\text { AIRS } \\
0.319\end{array}$}} & \multirow{2}{*}{\multicolumn{2}{|c|}{$\begin{array}{l}\text { AIRS } \\
0.307\end{array}$}} & \multirow{2}{*}{\multicolumn{3}{|c|}{$\begin{array}{l}\text { AIRS } \\
0.321\end{array}$}} \\
\hline & & & & & & & & & \\
\hline \multirow{2}{*}{$\tau_{\text {type }} \quad[\%]$} & $\mathrm{U}$ & M & $\mathrm{C}$ & $\mathrm{M}$ & $\mathrm{C}$ & $\mathrm{M}$ & $\mathrm{C}$ & 1 & $\mathrm{D}$ \\
\hline & 50 & 0 & 50 & 0 & 100 & 0 & 100 & & 0 \\
\hline$\left[{ }^{\circ}\right]$ & \multicolumn{2}{|c|}{23.35} & & & & & & 3.6 & \\
\hline$\left[{ }^{\circ}\right]$ & & & & & & & & 6.1 & \\
\hline$\left[^{\circ}\right]$ & 14 & & & & & & & 42.0 & \\
\hline
\end{tabular}

AERO: AERONET data from Goddard space flight center (MD) and Oklahoma State University (OK) AIRS: Aqua Atmospheric infrared sounder data (45 km resolution)

MOD/MYD: Terra or Aqua MODIS data (10 km resolution)

C,U,M,D: Continental, Urban, Maritime, Desert

SPOT-4 $20 \mathrm{~m}$ resolution radiances were acquired at $\sim 12.30 \mathrm{p} \mathrm{m}$. for $60 \mathrm{~km}$ x $60 \mathrm{~km}$ image swaths.

Dates and image specifications for the acquired Level 1A and 2A products are listed in Table 1. The level $2 \mathrm{~A}$ products are rectified to a standard cartographic projection (UTM WGS84) using cubic convolution resampling and the location accuracy is $\sim 30 \mathrm{~m}$ for the $\mathrm{HRG}$ and $\sim 350 \mathrm{~m}$ for the HRVIR imaging instruments (www.spot.com). However, convolution resampling averages neighboring pixels to provide a smoother appearance, thereby losing the original radiometric signal of the image pixels. To preserve the information content of the individual pixels, image-to-image rectification was applied to the level $1 \mathrm{~A}$ product (no geometric corrections performed) using the geolocated Level 2A product as reference and a nearest neighbor resampling technique. The native geolocation accuracy was improved using road networks and ground collected GPS data at road intersections.

The sensitivity to the received radiance signal is not spectrally uniform within the SPOT wavebands. Peak sensitivities are centered close to $545 \mathrm{~nm}, 650 \mathrm{~nm}$ and $835 \mathrm{~nm}$ for the green, red and near-infrared bands, respectively. However significant discrepancies may occur if only a center wavelength is input to REGFLEC (wavelength information is required for the $6 \mathrm{~S}$ radiative transfer and ACRM forward LUT runs). This is especially the case for the green waveband $(\sim 500-590 \mathrm{~nm})$ as the center region of this band is located in the canopy reflectance peak of green vegetation whereas reflectances decrease on either side of this peak (see Fig. 1b). Thus the use of only a center wavelength for the ACRM forward runs will cause modeled green reflectances (i.e. $545 \mathrm{~nm}$ ) to overestimate satellite observed band-averaged (i.e. $500-590 \mathrm{~nm}$ ) reflectances. To address this issue, $5 \mathrm{~nm}$ resolution spectral sensitivities (www.spot.com) were used to weight the spectral response of each band. While this procedure seems less critical for the red and near-infrared wavebands that see a near-linear change in the spectral reflectances (Fig. 1b), the incorporation of the spectral sensitivities is still important as model predictions of key vegetation parameters like leaf chlorophyll change as a result of subtle differences in canopy reflectance [11]. 


\subsection{Atmospheric state data}

Table 1 lists the values used for the atmospheric parameters required as input to the $6 \mathrm{~S}$ radiative transfer model (section 2.1). The level 2.0 AErosol RObotic NETwork (AERONET) aerosol optical depth $\left(\tau_{550}\right)$ and total precipitable water (TPW) data from nearby NASA GSFC (BARC study area) and Oklahoma State University (Fort Cobb study area) sites were used [62] except for the April $22^{\text {nd }}$ acquisition at Fort Cobb due to data unavailability. On this day $\tau_{550}$ was taken from the $10 \mathrm{~km}$ resolution Terra MODIS aerosol product (MOD04). MODIS aerosol data were also retrieved for the other acquisition dates and the generally good agreement with the sun photometer data (Table 1) suggests that MODIS derived $\tau_{550}$ values may be a good alternative when sun photometer data are unavailable. TPW data from the Atmospheric Infrared Sounder (AIRS) level 2 standard retrieval product were used on April $22^{\text {nd }}$. AIRS is a sounding instrument on board the Aqua satellite and derived atmospheric state parameters are reported at a spatial resolution of $45 \mathrm{~km} \times 45 \mathrm{~km}$ and represent midday conditions $(\sim 11.30$ a.m. to 2 p.m). The AIRS TPW product has been validated with an uncertainty estimate of 5-20\% (http://disc.sci.gsfc.nasa.gov/AIRS/documen-tation.shtml), and the retrievals for the other acquisition dates (Table 1) demonstrate a good agreement with the sun photometer measurements. Values of total ozone content $\left(\mathrm{O}_{3}\right)$ at the approximate time of the SPOT acquisitions were also obtained from the AIRS standard retrieval product.

\subsection{Land cover and soil map}

A key assumption in REGFLEC is that canopy characteristics (i.e. $N, S_{z}, \theta_{l}, C_{b p}$ ) are uniform within a given land cover class (section 3.2). A land cover map is thus needed to divide the region into a set of classes that satisfy this criterion. Actual knowledge of the specific land cover types (e.g. grassland, corn, wheat, soybean, deciduous forest) is not a prerequisite (specific land cover type information is not used in REGFLEC) but may improve the separation of the image into an appropriate set of classes.

For the BARC study area, field and forest boundaries were digitized manually using the $10 \mathrm{~m}$ resolution SPOT imagery as base map and land cover types assigned based on a rigorous windshield survey (classification accuracy $\sim 100 \%$ ). Less ground truth data on land cover type were available for the Fort Cobb study area; therefore, an unsupervised isodata classification was applied to the spectral datasets from the two SPOT acquisitions. The isodata classification is based on a number of input threshold parameters such as the minimum and maximum number of classes to define [63]. The classification was initially run with a large number of classes (i.e. 30 ) that subsequently were regrouped manually into a smaller set of classes (i.e. 9) using the available ground truth data. An overall classification accuracy of $79 \%$ resulted from comparing the classification result with the ground truth data using a confusion matrix approach.

In both study regions, care was taken to mask out urban areas and water bodies as these are likely to be identified as low vegetation density areas and thus may corrupt the initial estimation of the background reflectance signal (see section 3.1). A 2-pixel buffer zone was applied to vector maps of road transportation networks to mask out road contaminated pixels.

The extrapolation of soil parameter $\left(\mathrm{s}_{1}\right)$ retrievals for low vegetation density pixels to the entire region is accommodated by using a soil texture map (section 3.1). In this study, spatially distributed near-surface soil type data were derived from the State Soil Geographic Database (STATSGO) [64] 1-km multi-layered soil texture dataset for the continental U.S. (CONUS). The dataset consists of 9 soil classes (sand - clay) and contains 11 soil layers. Data from the top layer was used here. While this dataset provides soil type information at a coarse $(1 \mathrm{~km})$ resolution it is readily available for the U.S. and may be implemented as an integral component of REGFLEC to facilitate model implementation across the U.S. The dataset is assumed appropriate for capturing overall spatial trends in soil type (i.e. soil brightness/color) for the initial soil background correction (section 3.1). 


\section{RESULTS AND DISCUSSION}

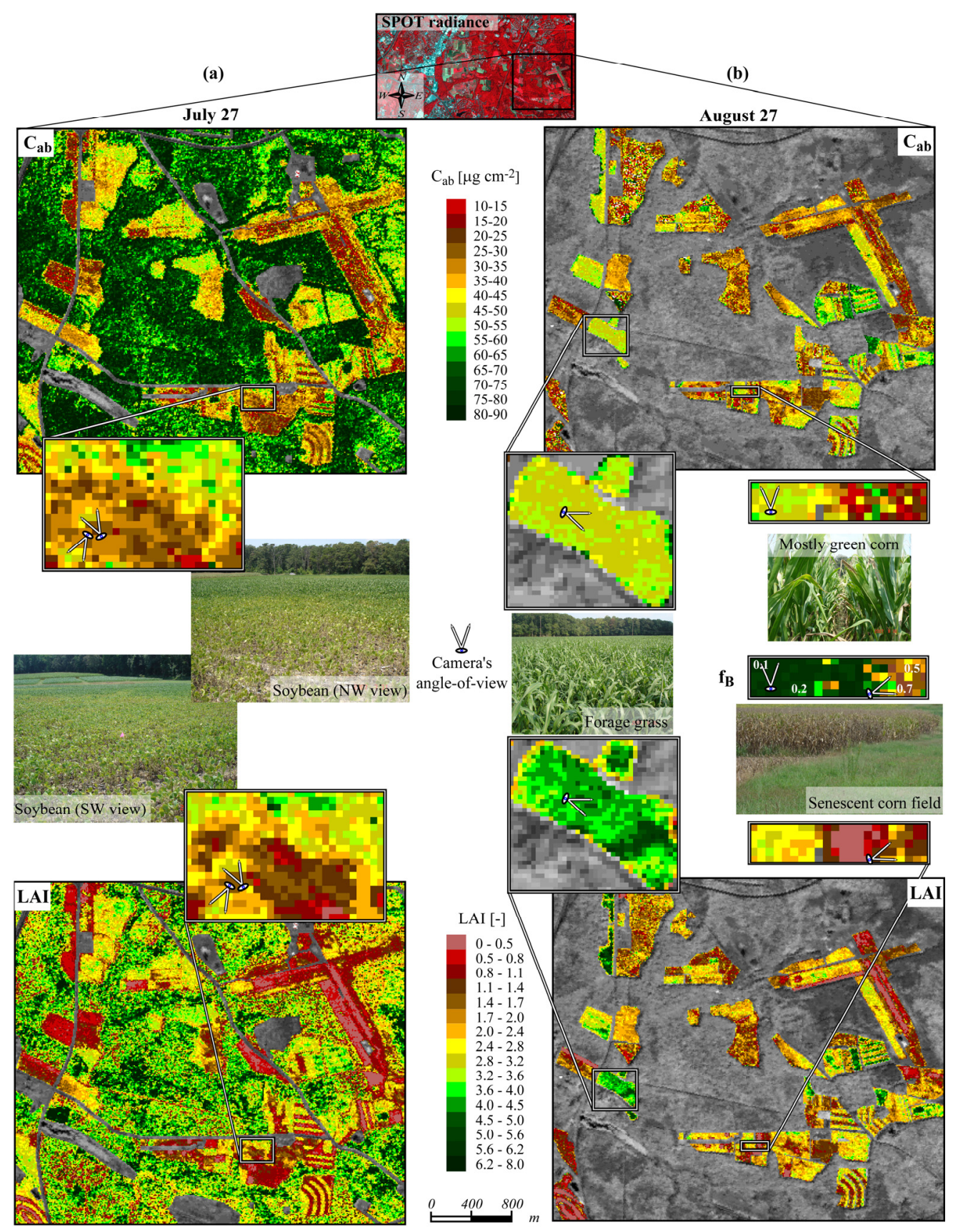

Fig. 6 REGFLEC derived maps of $10 \mathrm{~m}$ resolution leaf chlorophyll and LAI for a subset of the BARC study region at the July (a) and August (b) SPOT-5 acquisitions. Pixels with no retrievals have been filled with grey-scale near-infrared reflectance values and these pixels represent urban areas, water bodies, road networks or forested areas (b). 


\subsection{BARC study region}

Fig. 6 shows REGFLEC retrievals of LAI and Cab using $10 \mathrm{~m}$ resolution SPOT radiance data over a subset of the BARC study region. Urban areas, water bodies and road networks have been masked out in both images. The July $27^{\text {th }}$ image (Fig. 6a) includes LAI and $\mathrm{C}_{\mathrm{ab}}$ retrieval results for forested areas, while these have been omitted in the August $27^{\text {th }}$ image (Fig. 6b). This is because the upper bound in leaf chlorophyll (i.e. $80-90 \mu \mathrm{g} \mathrm{cm}^{-2}$ ) is reached for the majority of the forested pixels, which may reflect limitations in model applicability to forest canopies. While the homogeneous canopy reflectance model (ACRM) employed here has been applied to forest canopies [35,65], it does not explicitly account for the complex transfer of radiation within forest canopies and effects such as shading. The larger extinction of radiation in a deep forest canopy will decrease the spectral reflectances of a forest canopy compared to a homogeneous canopy with similar green leaf biomass levels. As a compensating effect, a homogeneous canopy reflectance model may underestimate LAI and overestimate leaf chlorophyll $[23,66]$. Ref. 43 also observed a tendency of the PROSPECT leaf optics model to overestimate $\mathrm{C}_{\mathrm{ab}}$ for a wide range of broad leaf tree species and found it necessary to recalibrate the PROSPECT specific absorption coefficients. The LAI forest retrievals, however, appear reasonable reaching maximum values on the order of 6 (Fig. 6a). This may be attributed to the high dry matter content $\left(150 \mathrm{~g} \mathrm{~m}^{-2}\right)$ adopted for forested areas in REGFLEC (a value of $50 \mathrm{~g} \mathrm{~m}^{-2}$ is used for cropland) as an increase in $C_{\mathrm{m}}$ will increase LAI thereby counteracting the LAI compensating effect [23].

Drought conditions throughout much of July imposed varying degrees of plant stress within intermediate to high vegetation density fields of soybean and corn and accelerating leaf senescence in many places. $\mathrm{C}_{\mathrm{ab}}$ and LAI show significant spatial heterogeneity within the depicted soybean field (zoomed views), varying from $\sim 10-70 \mu \mathrm{g} \mathrm{cm}{ }^{-2}$ and $\sim 0.5-4.5$, respectively (Fig. 6a). Photographs of the field reveal significant heterogeneity in $\mathrm{C}_{\mathrm{ab}}$ and LAI, and the model successfully detects the observed shift in $\mathrm{C}_{\mathrm{ab}}$ (i.e. leaf color) and leaf biomass along Northwesterly and Southwesterly transects (Fig. 6a).

Model estimates of leaf chlorophyll and LAI are on the order of $45 \mu \mathrm{g} \mathrm{cm}^{-2}$ and 4.0, respectively for the forage grass field highlighted in the August $27^{\text {th }}$ retrieval, and the more uniform spatial distribution agrees well with observations (photo) (Fig. 6b). The corn field also highlighted in Fig. 6b showed a strong east-west gradient in crop development, with
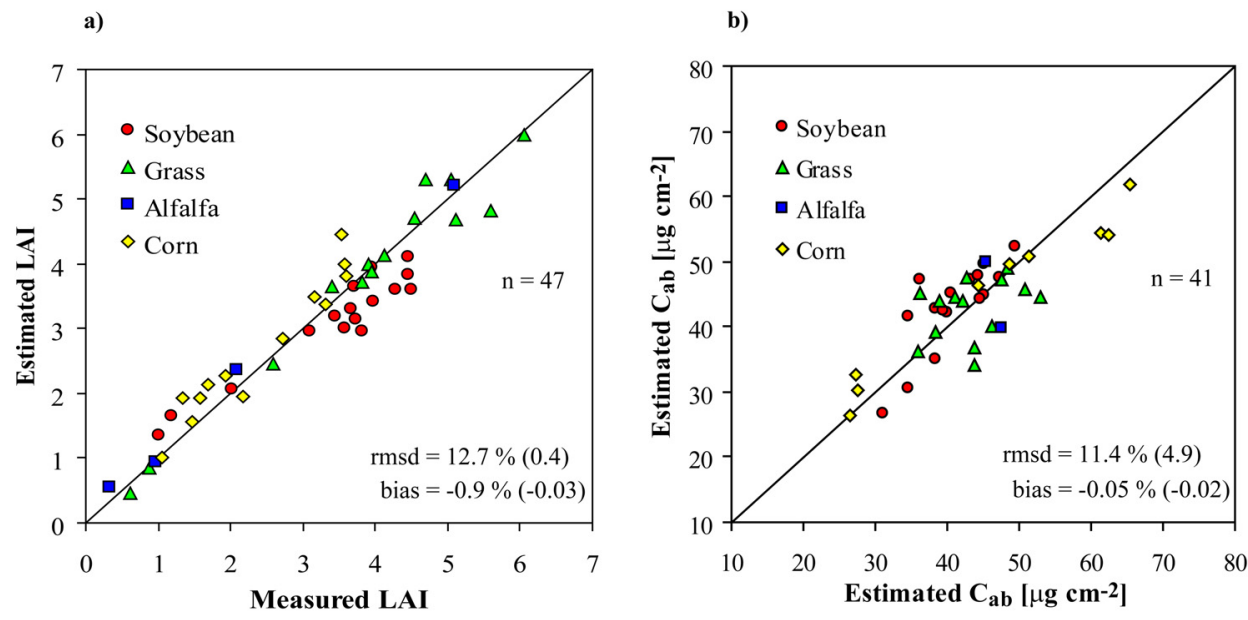

Fig. 7. Validation of LAI (a) and leaf chlorophyll (b) estimates for the BARC study region. The number of samples (n), and overall relative and absolute rootmean-square deviation (rmsd) and bias between estimates and measurements are listed. The thick line is the $1: 1$ line. 
advanced senescence in the eastern part of the field. REGLEC maps of $\mathrm{C}_{\mathrm{ab}}$, canopy fraction of senescent leaf material $\left(\mathrm{f}_{\mathrm{B}}\right)$ and LAI capture this gradient. $\mathrm{C}_{\mathrm{ab}}$, for example, is seen to change from $\sim 45 \mu \mathrm{g} \mathrm{cm}^{-2}$ to $\sim 20 \mu \mathrm{g} \mathrm{cm}^{-2}$ as the field conditions change from mostly green to partially senescent corn, with corresponding changes in REGLEC estimates of $f_{B}$.

For the purpose of validation, model estimates were averaged within a $2 \times 2$ pixel block around the center of each measurement plot to account for geolocation error and any mismatch between the point of measurement and the pixel dimensions. The ground-based $\mathrm{C}_{\mathrm{ab}}$ validation dataset was constructed using species-specific SPAD $-\mathrm{C}_{\mathrm{ab}}$ relationships if available; otherwise, the overall exponential fit was used (Fig. 5). A comparison between measurements collected within 5 days of the SPOT acquisitions with model estimates yields RMS deviations of $12.7 \%$ and $11.4 \%$ (of the mean observed value) for LAI and $\mathrm{C}_{\mathrm{ab}}$, respectively (Fig. 7a and b). The model successfully reproduces observed magnitudes and variances in leaf chlorophyll and LAI for a range of agricultural crops and over a wide range in leaf chlorophyll levels and vegetation density. Importantly, REGFLEC accurately retrieves LAI at high values $(>3)$ without suffering saturation effects common to NDVI-based retrievals. This can be attributed in part to the use of LAI - $\rho_{\text {nir }}$ relationships (section 3.3), as the near-infrared band remains responsive to changing leaf biomass in densely vegetated areas $[23,44]$. The $\mathrm{C}_{\mathrm{ab}}$ validation plot excludes data points with a measured LAI less than 0.8 , as the sensitivity of the green reflectance signal to leaf chlorophyll variations is very low for sparse vegetation canopies (see next section).

\subsection{Fort Cobb study region}

Fig. 8 displays REGFLEC maps of $\mathrm{C}_{\mathrm{ab}}$ and LAI at the time of the two SPOT-4 $(20 \mathrm{~m}$ resolution) acquisitions for a subset of the FC study region. REGFLEC was not run for urban areas, water bodies or road networks, which have been filled with a scaled near-infrared reflectance image in Fig. 8. At the time of the April overpass, the region is characterized by an equal mix of bare and intermediate to high vegetation density fields (Fig. 8a). The vegetated fields are dominated by irrigated wheat operations that typically employ an automated center pivot watering system (see for example the zoomed $\mathrm{C}_{\mathrm{ab}}$ view in Fig. 8a). Interestingly, in this case $C_{\mathrm{ab}}$ tends to be lower outside $\left(\sim 35 \mu \mathrm{g} \mathrm{cm}^{-2}\right)$ than inside $(\sim 45 \mu \mathrm{g} \mathrm{cm}$ $\left.{ }^{2}\right)$ the pivot even though high density wheat (LAI $\sim 5$ ) occupy the entire square (Fig. $8 \mathrm{a}$ ), which may indicate enhanced risk of stress conditions in the non-irrigated part of the wheat field.

The overall leaf chlorophyll content for the wheat fields is $41 \mu \mathrm{g} \mathrm{cm}^{-2}$ (std.dev $=10 \mu \mathrm{g}$ $\left.\mathrm{cm}^{-2}\right)$, whereas sparsely vegetated $(0.3<\mathrm{LAI}<1.0)$ and bare soil (LAI $\left.<0.3\right)$ areas are characterized by average $C_{a b}$ values of $26 \mu \mathrm{g} \mathrm{cm}^{-2}$ (std.dev $=14 \mu \mathrm{g} \mathrm{cm}^{-2}$ ) and $24 \mu \mathrm{g} \mathrm{cm}^{-2}$ (std.dev $=14 \mu \mathrm{g} \mathrm{cm}^{-2}$ ), respectively (Fig. 8a). The $\mathrm{C}_{\mathrm{ab}}$ results for the sparsely vegetated areas are questionable as reduced green reflectance sensitivity to leaf chlorophyll variations combined with increased sensitivity to soil background effects makes it extremely difficult to extract the leaf chlorophyll signal from the surface reflectance spectra $[10,11]$. The fact that the green reflectance signal is more responsive to leaf chlorophyll variations at low values of $\mathrm{C}_{\mathrm{ab}}$ (see Fig. 2g in Ref. 10) may explain the tendency towards low $\mathrm{C}_{\mathrm{ab}}$ levels for sparsely vegetated areas (Fig. 8a and b).

At the time of the second acquisition (Fig. 8b), vegetated fields represent primarily irrigated corn in a wide range of plant development stages, as well as irrigated cotton, peanuts and grass. The winter wheat fields have been harvested and are now tilled or untilled soil or sparsely vegetated. While the predominantly green and mature stands of corn and cotton (dark green pivots in Fig. 8b) have leaf chlorophyll values on the order of $55-70 \mu \mathrm{g} \mathrm{cm}^{-2}$, the senescing corn field displayed in Fig. 8b (zoomed view) is characterized by significantly reduced leaf chlorophyll levels. LAI (green + dead material) is estimated closely to 2.5 , the canopy fraction of senescent material is $\sim 0.25$, and bulk (i.e. $\mathrm{C}_{\mathrm{ab}} \times\left[1-\mathrm{f}_{\mathrm{B}}\right]$ ) leaf chlorophyll 
(a)
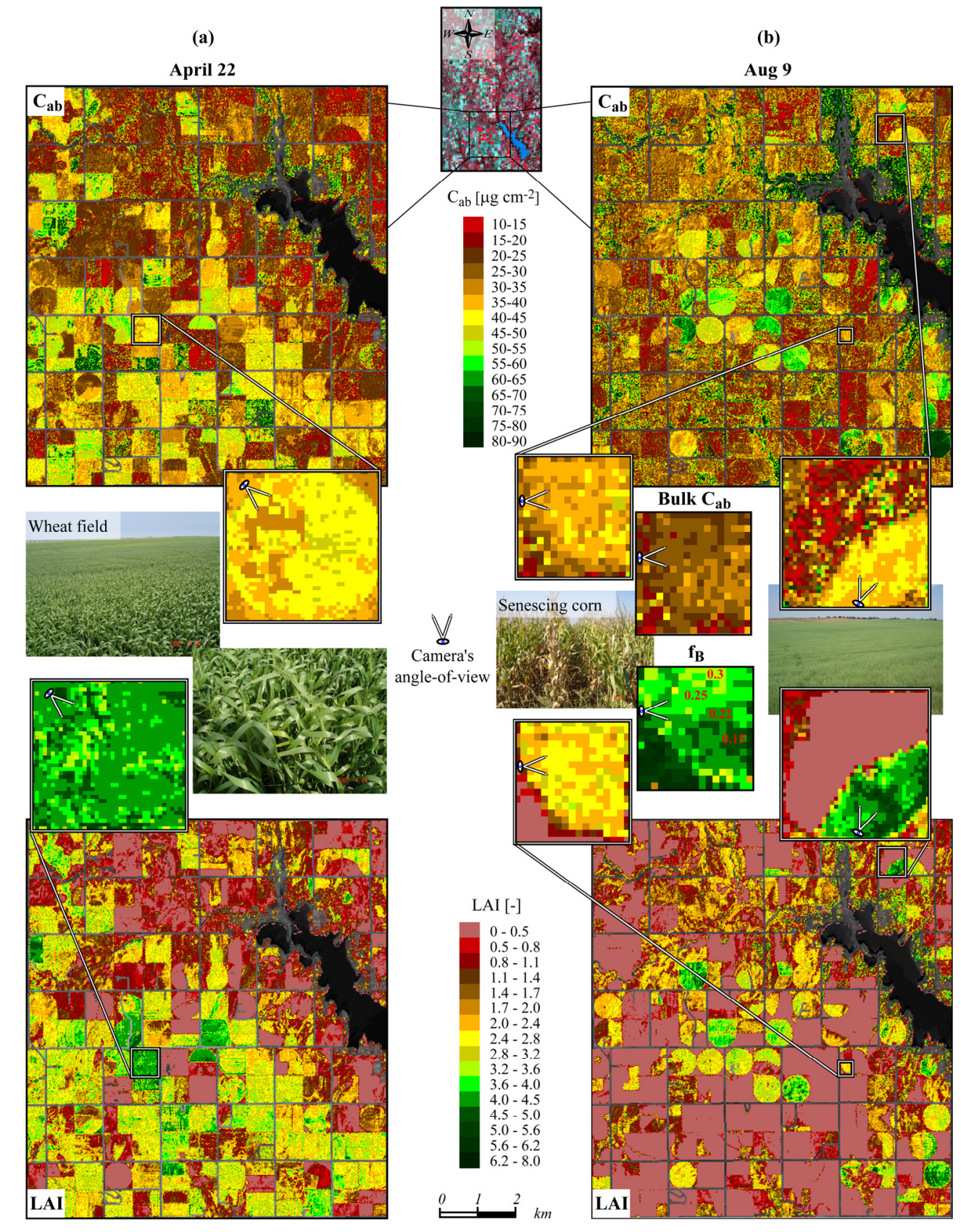

(b)

Fig. 8. REGFLEC derived maps of $20 \mathrm{~m}$ resolution leaf chlorophyll and LAI for a subset of the Fort Cobb study region at the April (a) and August (b) SPOT-4 acquisitions. Pixels with no retrievals have been filled with grey-scale nearinfrared reflectance values and these pixels represent urban areas, water bodies or road networks.

values are on the order of $25 \mu \mathrm{g} \mathrm{cm}$. This sensitivity demonstrates the potential of REGFLEC maps for general stress detection and crop management applications.

Also highlighted in Fig. $8 \mathrm{~b}$ is a grass crop grown under center pivot irrigation, with the remaining portion of the zoomed image in bare soil (visible in the far background in the 
a)

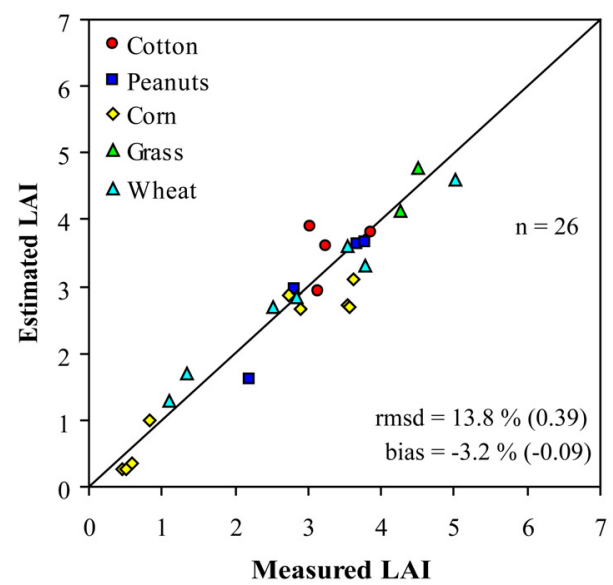

b)

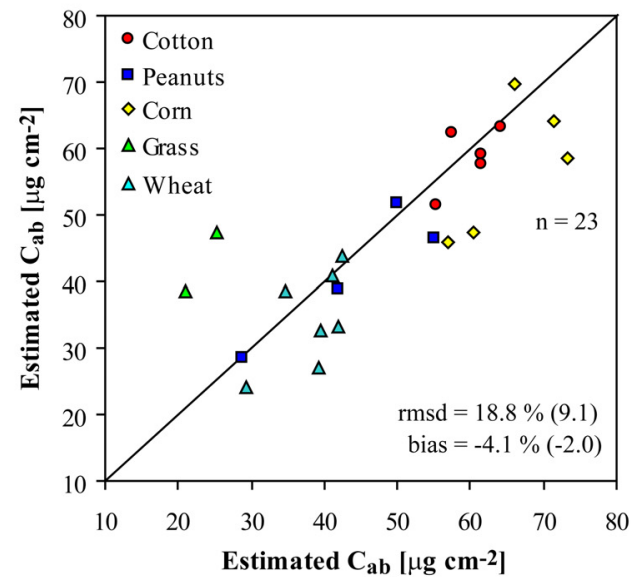

Fig. 9. Validation of LAI (a) and leaf chlorophyll (b) estimates for the Fort Cobb study region. The number of samples (n), and overall relative and absolute rootmean-square deviation (rmsd) and bias between estimates and measurements are listed. The thick line is the $1: 1$ line.

photo). The photo suggests a dense and homogeneous grass stand within the pivot circle, which is consistent with REGFLEC estimates of LAI $(\sim 4.3 \pm 0.4)$ and $\mathrm{C}_{\mathrm{ab}}\left(\sim 40 \pm 2 \mu \mathrm{g} \mathrm{cm}^{-2}\right)$.

As with the BARC region, REGFLEC estimates of LAI and $\mathrm{C}_{\mathrm{ab}}$ over Fort Cobb were validated using the average value of a $2 \times 2$ pixel block around the center of each measurement plot. The RMSD (13.8 and $18.8 \%$ for LAI and $\mathrm{C}_{\mathrm{ab}}$, respectively) and bias (-3.2 and $-4.1 \%$ ) in the Fort Cobb retrievals was larger than those found for BARC, with the largest $\mathrm{C}_{\mathrm{ab}}$ errors associated with the grass validation sites. While the bias increases $(-8.3 \%)$ the relative RMS deviation in $\mathrm{C}_{\mathrm{ab}}$ is reduced to $\left.13.8 \%(7.0 \mu \mathrm{g} \mathrm{cm})^{-2}\right)$ if the two grass validation sites are removed from the statistic analysis. This may reflect, in part, inaccuracy in the conversion of SPAD measurements into actual chlorophyll units; as a spectrophotometrical analysis of leaf samples from grass species wasn't performed there is no assurance that the established overall exponential fit between leaf chlorophyll content and SPAD values (Fig. 5) also applies to these fields. Improper separation of vegetation types may provide another explanation; mixing of land cover types with highly different leaf structural and canopy characteristics will introduce greater uncertainties in the retrieval of land cover specific parameters (section 3.2), which may result in biased leaf chlorophyll estimates. The $\mathrm{C}_{\mathrm{ab}}$ retrieval results were excellent for the BARC study region (Fig. 7b) where the land cover classification was done manually based on a rigorous visual inspection of the fields. The isodata-based classification applied at Fort Cobb (section 5.3) may have increased the likelihood of mixing individual land cover types. Despite these issues, REGFLEC $C_{a b}$ retrieval accuracies for the $\mathrm{FC}$ region still compare favorably to results reported in other studies on agricultural crops and grasses $[29,30,55,67]$.

\subsection{Land-cover specific parameter retrievals}

As detailed in section 3.2, REGFLEC assumes invariance of leaf structure $(N)$, Markov clumping parameter $\left(S_{z}\right)$, leaf inclination angle $\left(\theta_{l}\right)$, and brown pigment concentration $\left(C_{b p}\right)$ within a given land cover class. The values derived for these land-cover-specific parameters for agricultural cover types within the BARC and FC study regions are listed in Table 2 along with the average value of $f_{B}$ within each class. The results for the BARC area suggest little variation in derived leaf structure and Markov clumping characteristics between the corn, 
soybean, and grass cultivars. The value of $1.0-1.25$ for the leaf structure parameter is at the lower extreme of the reported range in $N$ and is lower than the value $(N=1.41)$ derived in Ref. 68 by inverting the PROSPECT model on measured corn reflectance and transmittance spectra, and values of 1.4 and 1.7 issued from PROSPECT inversions on corn and soybean leaf spectra, respectively [30]. Retrievals of $N$ for the FC region appear to be more in line with these indirect measurements (Table 2 ). However $N$ cannot be directly measured and a verifiable set of species-specific values does not exist.

A value of 1.0 is being consistently derived for $S_{z}$, which indicates a random distribution of vegetation elements within the canopy. While this is a reasonable approximation for the grass, wheat and soybean fields in the two study regions, values between 0.4 and 0.95 have been reported for row crops like corn and cotton $[48,69,70]$. Nevertheless, the random distribution assumption (i.e. $S_{z}=1.0$ ) resulted in excellent and largely unbiased agreements between REGFLEC LAI estimates and measurements made with the LAI-2000 for a wide range of canopies (Fig. 7a and 9a). While optical instruments like the LAI-2000 in principle provide effective rather than 'true' LAI [71], the employed measuring protocol for row crops (section 4.1) is believed to largely correct for deviations between effective and 'true' LAI for clumped canopies. However a thorough analysis on the relationship between measurements of LAI using non-destructive optical (LAI-2000) and destructive leaf sampling techniques may be needed to establish the nature (i.e. effective versus 'true') of the REGFLEC LAI estimates for the two study regions.

In REGFLEC $N, S_{z}, \theta_{l}$ and $C_{b p}$ are adjusted to arrive at LAI and $\mathrm{C}_{\mathrm{ab}}$ solutions that best satisfy the matching criteria described in section 3.2. While these estimates are likely to reflect actual leaf and canopy structural characteristics of a prescribed land cover class, model uncertainties (e.g. inversion technique, equation set and simplifying assumptions), land cover classification errors (mixing of cover types) and uncertainties in the reflectance data (e.g. due to radiometric and atmospheric correction) may cause deviations from the 'true' set of land cover specific parameter values. Ref. 10 discussed the effect of atmospheric effects on estimates of LAI and $\mathrm{C}_{\mathrm{ab}}$ and identified the choice of aerosol model (i.e. continental versus urban) as a particularly critical element. Ref. 65 tested the sensitivity of a neural-network radiative transfer model to uncertainty in the input reflectance and reported a relative difference between RMS deviations obtained using original and biased datasets (i.e. $\left[\mathrm{RMSD}_{\text {bias }}-\mathrm{RMSD}_{\text {orig }}\right] / \mathrm{RMSD}_{\text {orig }} \times 100$ ) of $41 \%$ for a reflectance bias of $+10 \%$. Similar test

Table 2. REGFLEC inverse estimates (section 3.2) of land cover specific canopy parameters for major cover types within the BARC and FC study regions. The average value of $f_{B}$ within each land cover class is also reported.

\begin{tabular}{llllllllllll}
\hline Land cover & $N$ & & $S_{z}$ & & $\theta_{l}$ & & $C_{b p}$ & & $\mathrm{f}_{\mathrm{B}}$ & \\
\hline \multicolumn{1}{c}{$B A R C$} & $J u l$ & $A u g$ & $J u l$ & $A u g$ & $J u l$ & $A u g$ & $J u l$ & $A u g$ & $J u l$ & $A u g$ \\
Corn & 1.25 & 1.0 & 1.0 & 1.0 & 70 & 70 & 2.5 & 4.5 & 0.09 & 0.34 \\
Soybean & 1.0 & 1.0 & 1.0 & 1.0 & 70 & 70 & 4.0 & 4.5 & 0.08 & 0.10 \\
Alfalfa & - & 1.5 & - & 1.0 & - & 70 & - & 4.5 & - & 0.09 \\
Grass & 1.0 & 1.0 & 1.0 & 1.0 & 70 & 70 & 2.5 & 4.5 & 0.09 & 0.02 \\
$\quad$ FC & $A p r$ & $A u g$ & $A p r$ & $A u g$ & $A p r$ & $A u g$ & $A p r$ & $A u g$ & $A p r$ & $A u g$ \\
Wheat & 1.5 & - & 1.0 & - & 70 & - & 4.5 & - & 0.12 & - \\
Corn & - & 1.5 & - & 1.0 & - & 55 & - & 4.5 & - & 0.14 \\
Cotton & - & 1.75 & - & 1.0 & - & 70 & - & 4.5 & - & 0.14 \\
Peanuts & - & 1.5 & - & 1.0 & - & 70 & - & 4.5 & - & 0.12 \\
Grass & - & 1.25 & - & 1.0 & - & 55 & - & 4.5 & - & 0.15 \\
\hline
\end{tabular}


(a)
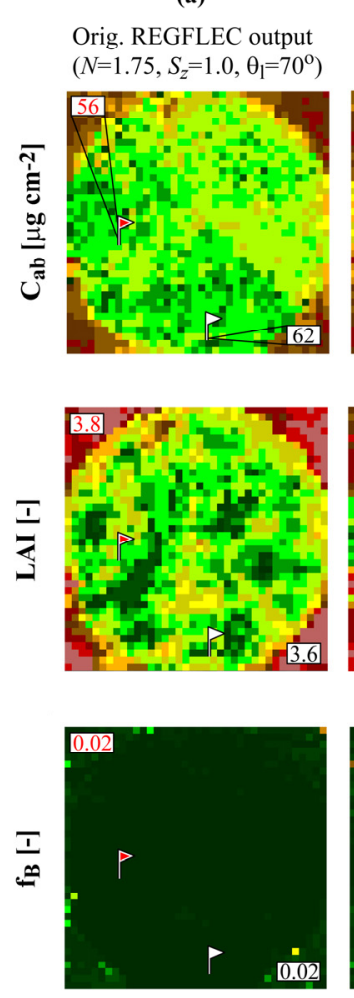

(b)
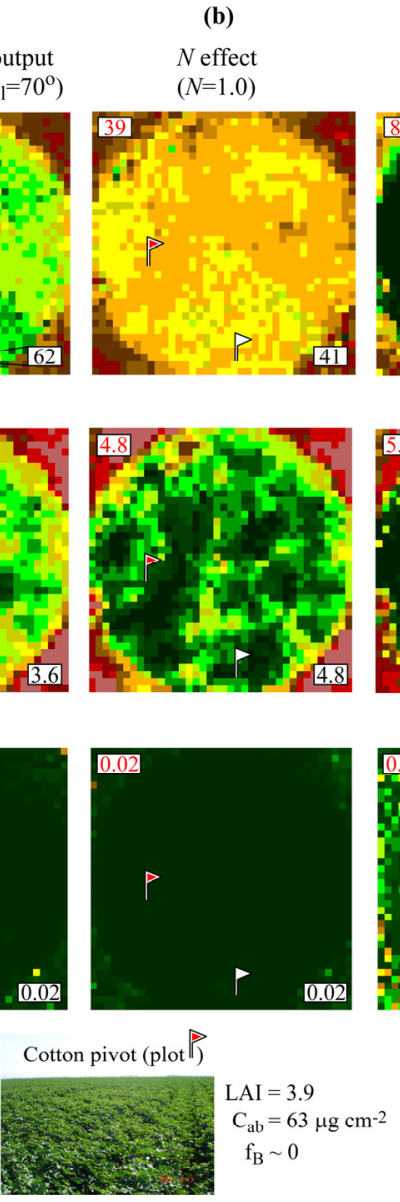

(c)
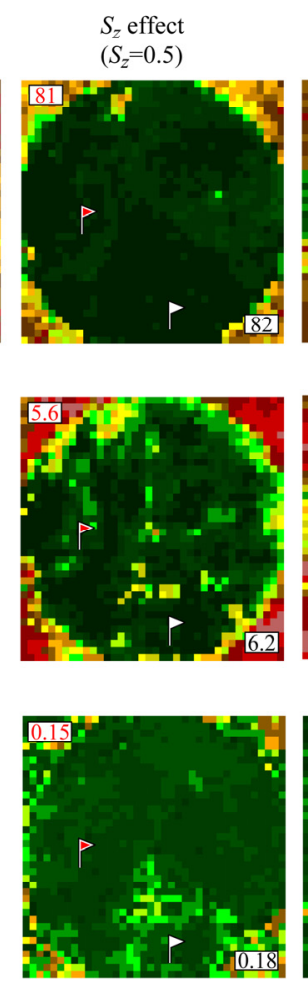

(d)
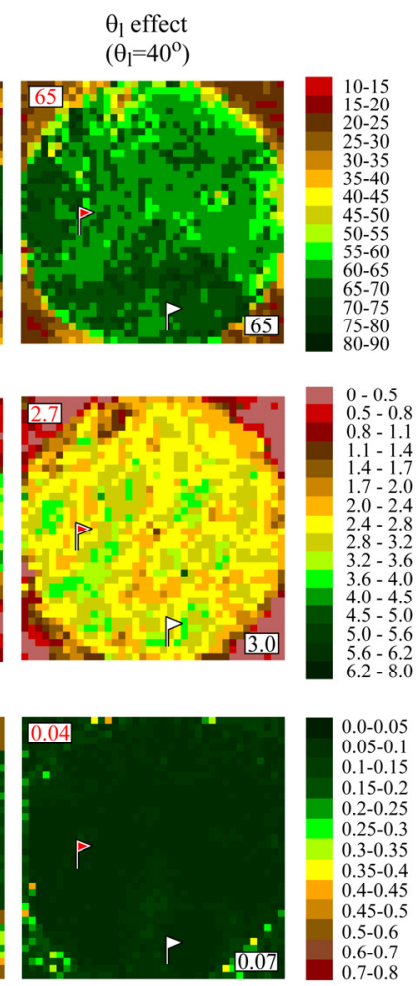

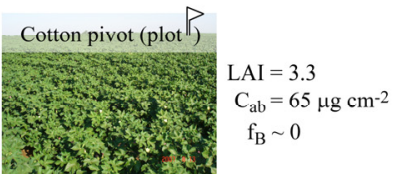

Fig. 10 a) REGFLEC output results of $\mathrm{C}_{\mathrm{ab}}$, LAI and $\mathrm{f}_{\mathrm{B}}$ for a cotton pivot within the Fort Cobb study region. The sensitivity of the output results to variations in $N$ (b), $S_{z}$ (c) and $\theta_{l}$ (d) is shown. For each simulation the exact values of $\mathrm{C}_{\mathrm{ab}}$, LAI and $f_{B}$ are provided for two sites within the field where measurements were made. Photos of the two field plots are provided at the bottom along with the in-situ measurements at each site.

simulations with REGFLEC resulted in a RMSD difference of only $15 \%$ for LAI and $16 \%$ for $\mathrm{C}_{\mathrm{ab}}$ for a reflectance uncertainty of $+10 \%$. REGFLEC partially compensates for input reflectance errors by adjusting the land cover specific parameters; the Fort Cobb corn and cotton land cover types, for example, saw $N$ increase to 1.75 (from 1.5) and 2.0 (from 1.75), respectively as a result of adding a $10 \%$ error to the surface reflectance dataset. Thus despite apparent discrepancies in the land cover specific retrievals, the REGFLEC retrieval system may not benefit from site-specific in-situ calibration data (if available) as $\mathrm{N}, S_{z}, \theta_{l}$ and $C_{b p}$ function more as an internal calibration of the model system. This is also supported by the overall high LAI and $\mathrm{C}_{\mathrm{ab}}$ retrieval accuracies previously reported.

Fig. 10 shows original REGFLEC output results $\left(C_{a b}\right.$, LAI and $\left.f_{B}\right)$ for a cotton pivot within the FC study region and demonstrates how variations in $N, S_{z}$ and $\theta_{l}$ from their originally derived value $(1.75,1.0,70$, respectively) affect the output maps. For each simulation the modeled values of $\mathrm{C}_{\mathrm{ab}}$, LAI and $\mathrm{f}_{\mathrm{B}}$ are provided for two sites within the field where measurements were made. The original REGFLEC simulations at the two field plots (red and white flag) indicate a canopy of green leaves $\left(f_{B} \sim 0.02\right)$ characterized by a LAI of 
3.6 - 3.8 and a $\mathrm{C}_{\mathrm{ab}}$ of $56-62 \mu \mathrm{g} \mathrm{cm}^{-2}$, which agrees well with the observed values of $3.3-3.9$ and $63-65 \mu \mathrm{g} \mathrm{cm}^{-2}$, respectively (Fig. 10a). Changing the value of $N$ from 1.75 to 1.0 causes a significant decrease in $\mathrm{C}_{\mathrm{ab}}(\sim 32 \%)$, LAI responds with a $\sim 30 \%$ increase, whereas $\mathrm{f}_{\mathrm{B}}$ remains largely unchanged (Fig. 10b). This response of $\mathrm{C}_{\mathrm{ab}}$ and LAI to a decrease in $N$ is explained by a resultant decrease in simulated green and near-infrared reflectance $[23,72]$ as a function of $\mathrm{C}_{\mathrm{ab}}$ and LAI, respectively. As a result discrepancies between estimates and observations of $\mathrm{C}_{\mathrm{ab}}$ and LAI increase (Fig. 10b).

The clumping effect was investigated by changing $S_{z}$ from 1.0 (no clumping) to 0.5 (significant clumping). REGFLEC compensates by increasing $\mathrm{C}_{\mathrm{ab}}$, LAI and $\mathrm{f}_{\mathrm{B}}$ to unrealistic levels; at the field plot with the white flag measurements of $\mathrm{C}_{\mathrm{ab}}$, LAI and $\mathrm{f}_{\mathrm{B}}$ are overestimated at $17 \mu \mathrm{g} \mathrm{cm}{ }^{-2}(26 \%), 2.9(88 \%)$ and 0.18 , respectively (Fig. 10c). While variations in $\theta_{l}$ appear to have a relatively minor influence on $\mathrm{C}_{\mathrm{ab}}$, LAI values are seen to decrease significantly as the canopy changes from an erectophile to a predominantly planophile leaf angle distribution (Fig. 10d). Evidently, REGFLEC output results are highly sensitive to the choice of parameter values and in this case REGFLEC arrived at a set of land cover specific parameters $\left(N=1.75, S_{z}=1.0, \theta_{l}=70\right)$ that allow for realistic retrievals of $\mathrm{C}_{\mathrm{ab}}$, LAI and $\mathrm{f}_{\mathrm{B}}$ (Fig. 10a).

\subsection{Comparison with empirical models}

This section investigates the retrieval accuracies obtainable by standard empirical approaches in order to provide a comparison with the performance results of the physically-based REGFLEC model. Fig. 11 demonstrates the correlation of measurements of LAI with atmospherically corrected satellite observations of NDVI, GNDVI and near-infrared reflectance for the two study regions. As expected, LAI is reasonably correlated with NDVI

(a)
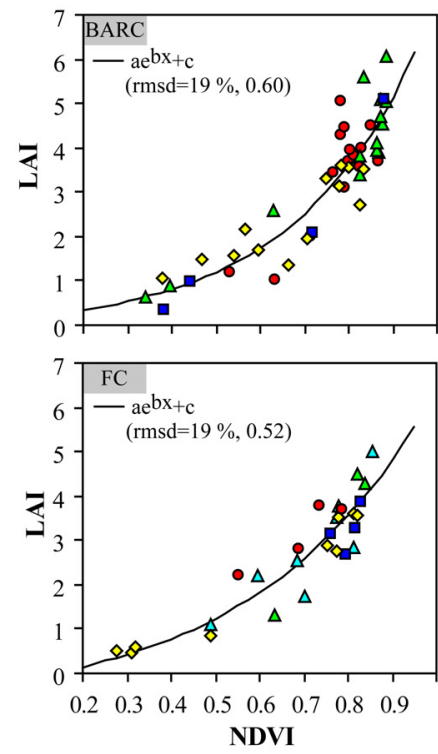

(b)
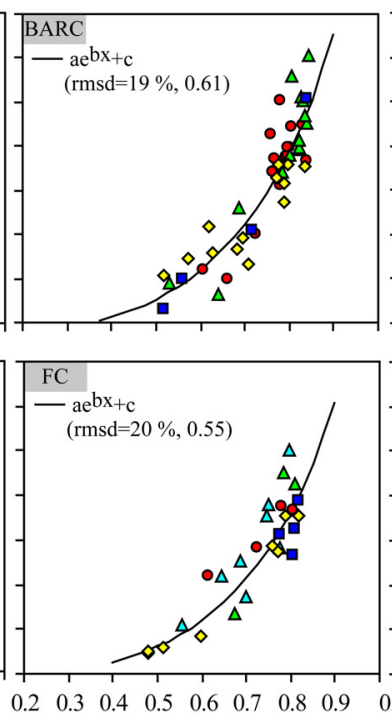

GNDVI (c)
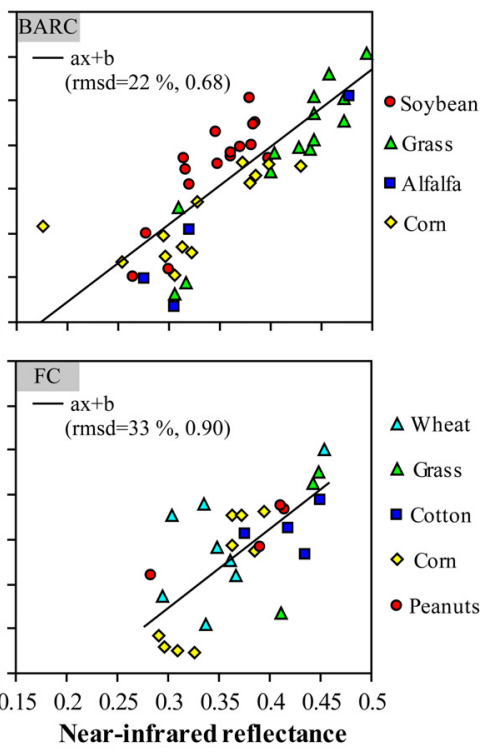

Fig. 11 Correlation between in-situ measurements of LAI and atmospherically corrected satellite observations of NDVI, GNDVI and near-infrared reflectance for BARC and FC study regions. The relative and absolute root-mean-square deviation (rmsd) is listed along with the type of regression model. 
and GNDVI (Fig. 11a and b) and the exponential regression analysis produces overall relative RMS deviations on the order of $19 \%$ (Fig. 11). The uncertainty estimates are likely to be at the low end as an independent LAI dataset was not available for validation.

While the normalized vegetation index relationships approach a saturation level at intermediate LAI values $(\sim 3-4)$, the near-infrared reflectances tend to increase more linearly with increasing leaf biomass (Fig. 11c). However the increased LAI sensitivity of the nearinfrared band is not evident from an empirical-statistical standpoint (RMSD $=22 \%$ and $33 \%$, respectively) being the result of confounding factors. Variations in soil reflectance, canopy characteristics, and external conditions significantly influence the near-infrared reflectance signal and multiple soil and land cover specific LAI $-\rho_{\text {nir }}$ relationships are needed to effectively utilize the added information content of the $\rho_{\text {nir }}$ band [10]. For both study regions, REGFLEC LAI retrieval accuracies were higher than achievable by any of the empirical models displayed in Fig. 11.

While changes in leaf chlorophyll induce large differences in green spectrum canopy reflectance $[13,73]$ these changes are also confounded by key factors such as soil background, canopy architecture and LAI $[10,11]$. The complex nature of leaf chlorophyll retrieval from canopy reflectance spectra can be clearly envisaged from the largely uncorrelated relationships between measurements of leaf chlorophyll and satellite observations of green reflectance (Fig. 12a). Empirical relationships are typically more successful at predicting total canopy chlorophyll content (i.e. $\mathrm{LAI}_{\mathrm{green}} \times \mathrm{C}_{\mathrm{ab}}$ ) using an index such as the Gitelson green index (GI) that combines the chlorophyll sensitive green band and LAI sensitive near-infrared

(a)

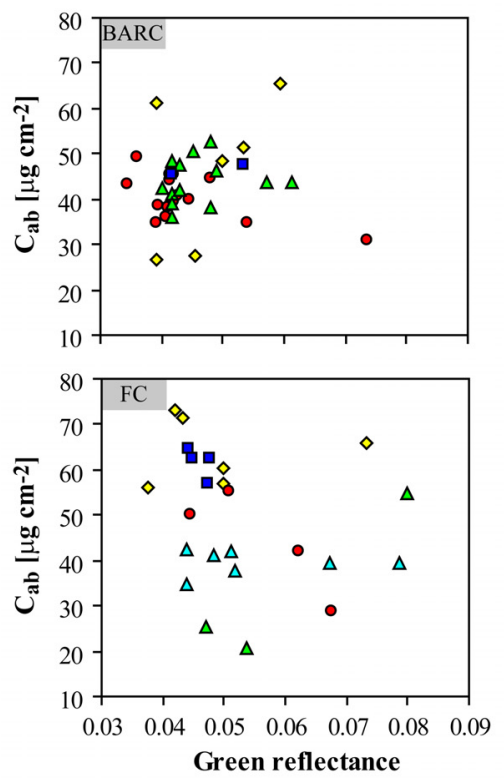

(b)
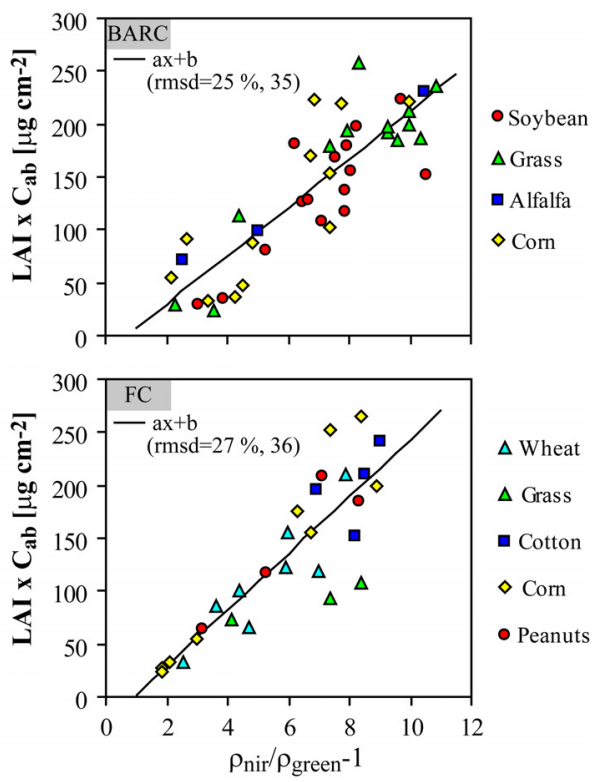

Fig. 12 a) Correlation between in-situ measurements of leaf chlorophyll content and atmospherically corrected satellite observations of green reflectance for BARC and $\mathrm{FC}$ study regions. b) Correlation between measurements of total canopy chlorophyll content (i.e. $\mathrm{LAI}_{\text {green }} \times \mathrm{C}_{\mathrm{ab}}$ ) and the Gitelson green index $\left(\rho_{\text {nir }} / \rho_{\text {green }}-1\right)$. The relative and absolute root-mean-square deviation (rmsd) is listed along with the type of regression model. 
band $\left(\rho_{\text {nir }} / \rho_{\text {green }}-1\right)$ [45]. Still these relationships are characterized by significant scatter (relative RMS deviations between 25 and 27\%) due to unresolved influences of e.g. canopy architecture, leaf structure and background effects (Fig. 12b). In fact, GI exhibit a higher correlation (i.e. $\left.\mathrm{r}^{2}\right)$ with $\mathrm{LAI}_{\text {green }}$ than with $\mathrm{LAI}_{\text {green }} \times \mathrm{C}_{\mathrm{ab}}$ in the BARC $(0.83$ versus 0.74$)$ and FC ( 0.76 versus 0.74$)$ study regions suggesting little use of the index for detecting variations in chlorophyll unless confounding factors are accounted for. However the derivation of total canopy chlorophyll may not be as straightforward as $\mathrm{LAI}_{\mathrm{green}} \times \mathrm{C}_{\mathrm{ab}}$ suggests as vertical gradients in leaf chlorophyll commonly occur within canopies [45,74].

While empirical or semi-empirical approaches have been shown to be useful for also generating robust and more generally applicable VI relationships, especially when employing narrowband hyperspectral indices [11,42,74] and reflectances in the red edge spectrum $[16,45]$, the results from this study demonstrate the encouraging utility of a non-calibrated (non-empirical) integrated (atmosphere - canopy - leaf) radiative transfer model for separating the LAI and leaf chlorophyll signal from standard (i.e. green, red and nearinfrared) broadband canopy reflectance spectra over a diversity of land cover types.

\section{CONCLUSIONS}

The regularized canopy reflectance modeling tool (REGFLEC) was effectively implemented at the regional scale using a new LUT-based inversion strategy that incorporates various techniques for constraining the retrieval of LAI and leaf chlorophyll from canopy reflectance spectra. The integrated system of radiative transfer models (atmosphere - canopy - leaf) facilitates canopy biophysical retrievals directly from at-sensor radiance data in three broad spectral bands (green, red and near-infrared) present on most airborne and operational satellite sensors. The model system requires no calibration and may be run for any locality with availability of standard atmospheric state data (i.e. aerosol optical depth, aerosol type, precipitable water vapor, ozone content), a land cover classification and soil map.

REGFLEC was applied to study regions in Maryland and Oklahoma using 10 and $20 \mathrm{~m}$ resolution SPOT-5 and SPOT-4 radiance data, respectively. The model was able to reproduce visible (i.e. from photographs) spatial patterns in vegetation density and leaf chlorophyll (i.e. greenness) within stressed and/or partially senescent agricultural fields. REGFLEC demonstrated robust retrieval capabilities for a mosaic of land cover types (wheat, corn, soybean, cotton, alfalfa, grass, peanuts) over a wide range in leaf chlorophyll levels $\left(20<\mathrm{C}_{\mathrm{ab}}\right.$ $<75)$ and vegetation density $(0<\mathrm{LAI}<6)$ and for conditions with intermixing of green and senescent leaf material and soil background interference. Reported relative RMS deviations between estimates and in-situ measurements were lower for LAI (13-14 \%) than for $\mathrm{C}_{\mathrm{ab}}(11$ - $19 \%$ ), which is expected considering the added complexity in extracting the leaf chlorophyll signal from canopy reflectance spectra. Since the leaf chlorophyll retrievals rely on absolute green reflectance values they are more likely to be affected by errors/uncertainties in satellite data calibration, atmospheric correction, and model formulation than are the LAI retrievals that depend partly on normalized vegetation index formulations. A good land cover map that properly separates land cover types with contrasting canopy characteristics is also critically important for high fidelity $\mathrm{C}_{\mathrm{ab}}$ retrievals as the choice of land cover-specific parameter settings (i.e. leaf mesophyll structure, vegetation clumping, leaf inclination angle) can have a significant impact on $\mathrm{C}_{\mathrm{ab}}-\rho_{\text {green }}$ relationships.

Overall the regional-scale biophysical maps demonstrated impressive utility in detecting spatial and temporal variations in LAI and $\mathrm{C}_{\mathrm{ab}}$ as a result of vegetation type, vegetation stress and plant development stage. Site-specific data for calibration of REGFLEC are not needed and the physical approach has the potential of being more universally applicable than traditional empirical approaches.

Future work will involve more detailed studies on the application of REGFLEC in forested areas where particularly leaf chlorophyll estimates appear positively biased. 
REGFLEC may potentially be run at a range of spatial and temporal scales using at-sensor radiance observations from airborne sensor systems such as CASI, SpecTIR, and HyMap and operational satellite sensors such as MODIS, Landsat TM/ETM+, SPOT, and MERIS. Thus possible application areas are manifold and REGFLEC derived variables may assist precision crop management and drought and vegetation productivity monitoring at larger scales.

\section{Acknowledgments}

Funding for this research was provided by the USDA Agricultural Research Service Research Associate Program. We would like to acknowledge Wayne Dulaney and Principal Investigator Brent Holben of the AERONET sites for making sun photometer data available. Trade names are included for the benefit of the reader and do not imply an endorsement of or a preference for the product listed by the U.S. Department of Agriculture.

\section{References}

[1] G. B. Bonan, "Land-atmosphere interactions for climate system models: coupling biophysical, biogeochemical, and ecosystem dynamical processes", Remote Sens. Environ. 51, 57-73 (1995) [doi:10.1016/0034-4257(94)00065-U].

[2] R. M. Houborg, and H. Soegaard (2004), "Regional simulation of ecosystem $\mathrm{CO}_{2}$ and water vapour exchange for agricultural land using NOAA AVHRR and Terra MODIS satellite data. Application to Zealand, Denmark", Remote Sens. Environ 93, 150-167 (2004) [doi:10.1016/j.rse.2004.07.001].

[3] S. M. Moran, S. J. Maas, and P. J. Pinter Jr., "Combining remote sensing and modeling for estimating surface evaporation and biomass production", Remote Sens. Reviews 12, 335- 353 (1995).

[4] J. M. Norman, W. P. Kustas, and K. S. Humes, "A two-source approach for estimating soil and vegetation energy fluxes from observations of directional radiometric surface temperature", Agric. For. Meteorol. 77, 263-293 (1995) [doi:10.1016/0168-1923(95)02265-Y].

[5] E. Boegh, H. Soegaard, N. Broge, C. B. Hasager, N. O. Jensen, K. Schelde, and A. Thomsen, "Airborne multispectral data for quantifying leaf area index, nitrogen concentration, and photosynthetic efficiency in agriculture", Remote Sens. Environ. 81, 179-193 (2002) [doi:10.1016/S0034-4257(01)00342-X].

[6] I. Nijs, T. Behaeghe, and I. Impens, "Leaf nitrogen content as a predictor of photosynthetic capacity in ambient and global change conditions", J. Biogeogr. 22, 177-183 (1995) [doi:10.2307/2845908].

[7] G. A. Carter, "Ratios of leaf reflectances in narrow wavebands as indicators of plant stress", Int. J. Remote Sens. 15, 697-704 (1994) [doi:10.1080/01431169408954109].

[8] J. Penuelas, and I. Filella, "Visible and near-infrared reflectance techniques for diagnosing plant physiological status", Trends Plant Sci. 3, 151-156 (1998) [doi:10.1016/S1360-1385(98)01213-8].

[9] P. J. Zarco-Tejada, J. R. Miller, G. H. Mohammed, T. L. Noland, and P. H. Sampson, "Vegetation stress detection through chlorophyll $\mathrm{a}+\mathrm{b}$ estimation and fluorescence effects on hyperspectral imagery", J. Environ. Qual. 31, 1433-1441 (2002).

[10] R. Houborg, M. Anderson, and C. Daughtry, "Utility of an image-based canopy reflectance modeling tool for remote estimation of LAI and leaf chlorophyll content at the field scale", Remote Sens. Environ. 113, 259-274 (2009) [doi:10.1016/j.rse.2008.09.014].

[11] C. S. T. Daughtry, C. K. Walthall, M. S. Kim, E. Brown de Costoun, and J. E. McMurtrey III "Estimating corn leaf chlorophyll concentration from leaf and canopy 
reflectance", Remote Sens. Environ. 74, 229-239 (2000) [doi:10.1016/S00344257(00)00113-9].

[12] I. Filella, L. Serrano, J. Serra, and J. Penuelas, "Evaluating wheat nitrogen status with canopy reflectance indices and discriminant analysis", Crop Sci. 35, 1400-1405 (1995).

[13]B. J. Yoder, and R. E. Pettigrew-Crosby, "Predicting nitrogen and chlorophyll concentrations from reflectance spectra $(400-2500 \mathrm{~nm})$ at leaf and canopy scales", Remote Sens. Environ. 49, 81-91 (1995) [doi:10.1016/0034-4257(94)90061-2]

[14] A. A. Gitelson, A. Vina, S. B. Verma, D. C. Rundquist, T. J. Arkebauer, G. Keydan, B. Leavitt, V. Ciganda, G. G. Burba, and A. Suyker, "Relationship between gross primary production and chlorophyll content in crops: Implications for the synoptic monitoring of vegetation productivity", J. Geophys. Res. 111, D08S11, (2006) [doi:10.1029/2005JD006017].

[15] Y. Yi, D. Yang, J. Huang, and D. Chen, "Evaluation of MODIS surface reflectance products for wheat leaf area index (LAI) retrieval", ISPRS J. Photogramm. 63, 661677 (2008) [doi:10.1016/j.isprsjprs.2008.04.004].

[16]N. H. Broge, and J. V. Mortensen, "Deriving green crop area index and canopy chlorophyll density of winter wheat from spectral reflectance data", Remote Sens. Environ. 81, 45-57 (2002) [doi:10.1016/S0034-4257(01)00332-7].

[17]T. N. Carlson, and D. A. Ripley, "On the relation between NDVI, fractional vegetation cover, and leaf area index", Remote Sens. Environ. 62, 241- 252 (1997) [doi:10.1016/S0034-4257(97)00104-1].

[18] R. B. Myneni, S. Maggion, J. Iaquinta, J. L. Privette, N. Gobron, B. Pinty, D. S. Kimes, M. M. Verstraete, and D. L. Williams, " Optical remote sensing of vegetation: Modeling, caveats, and algorithms", Remote Sens. Environ. 51, 169-188 (1995) [doi:10.1016/0034-4257(94)00073-V].

[19] C. J. Tucker, "Remote sensing of leaf water content in the near infrared", Remote Sens. Environ. 10, 23-32 (1980) [doi:10.1016/0034-4257(80)90096-6].

[20]F. Baret, and G. Guyot, "Potentials and limits of vegetation indices for LAI and APAR assessment", Remote Sens. Environ. 35, 161-173 (1991) [doi:10.1016/00344257(91)90009-U].

[21] R. Colombo, D. Bellingeri, D. Fasolini, and C. M. Marino, "Retrieval of leaf area index in different vegetation types using high resolution satellite data", Remote Sens. Environ. 86, 120-131 (2003) [doi:10.1016/S0034-4257(03)00094-4].

[22] N. Gobron, B. Pinty, and M. M. Verstraete, "Theoretical limits to the estimation of the leaf area index on the basis of visible and near-infrared remote sensing data", IEEE T. Geosci. Remote 35, 1438-1445 (1997) [doi:10.1109/36.649798].

[23] R. Houborg, H. Soegaard, and E. Boegh, "Combining vegetation index and model inversion methods for the extraction of key vegetation biophysical parameters using Terra and Aqua MODIS reflectance data", Remote Sens. Environ. 106, 39-58 (2007) [doi:10.1016/j.rse.2006.07.016].

[24] Y. J. Kaufman, D. D. Herring, K. J. Ranson, and G. J. Collatz, "Earth observing system AM1 mission to earth", IEEE T. Geosci. Remote 36, 1045-1055 (1998) [doi:10.1109/36.700989].

[25] A. Berk, G. P. Anderson, P. K. Acharya, L. S. Bernstein, L. Muratov, J. Lee, M. Fox, S. M. Adler-Golden, J. H. Chetwynd, M. L. Hoke, R. B. Lockwood, J. A. Gardner, T. W. Cooley, C. C. Borel, and P. E. Lewis, "MODTRAN 5: a reformulated atmospheric band model with auxiliary species and practical multiple scattering options: update", Proc. SPIE 5806, 662-667 (2005) [doi: $10.1117 / 12.606026]$.

[26] S. Y. Kotchenova, and E. F. Vermote, "Validation of a vector version of the $6 \mathrm{~S}$ radiative transfer code for atmospheric correction of satellite data. Part II: 
Homogeneous Lambertian and anisotropic surfaces", Appl. Optics 46, 4455-4464 (2007) [doi:10.1364/AO.46.004455].

[27] B. N. Holben, D. Tanre, A. Smirnov, T. F. Eck, I. Slutsker, N. Abuhassan, W. W. Newcomb, J. S. Schafer, B. Chatenet, F. Lavenu, Y. J. Kaufman, J. V. Castle, A. Setzer, B. Markham, D. Clark, R. Frouin, R. Halthore, A. Karneli, N. T. O’Neill, C. Pietras, R. T. Pinker, K. Voss, and G. Zibordi, "An emerging ground-based aerosol climatology: Aerosol optical depth from AERONET", J. Geophys. Res. 106, 12067 12097 (2001) [doi:10.1029/2001JD900014].

[28]E. F. Vermote, N. Z. El Saleous, and C. O. Justice, "Atmospheric correction of MODIS data in the visible to middle infrared: first results", Remote Sens. Environ. 83, 97 - 111 (2002) [doi:10.1016/S0034-4257(02)00089-5].

[29] S. Jacquemoud, F. Baret, B. Andrieu, F. M. Danson, and K. Jaggard, "Extraction of vegetation biophysical parameters by Inversion of the PROSPECT + SAIL models on sugar beet canopy reflectance data. Application to TM and AVIRIS sensors", Remote Sens. Environ.52, 163-172 (1995) [doi:10.1016/0034-4257(95)00018-V].

[30] S. Jacquemoud, C. Bacour, H. Poilvé, and J.-P. Frangi, "Comparison of Four Radiative Transfer Models to Simulate Plant Canopies Reflectance: Direct and Inverse Mode", Remote Sens. Environ. 74, 471-481 (2000) [doi:10.1016/S00344257(00)00139-5].

[31] B. Combal, F. Baret, M. Weiss, A. Trubuil, D. Macé, A. Pragnère, R. Myneni, Y. Knyazikhin, and L. Wang, "Retrieval of canopy biophysical variables from bidirectional reflectance using prior information to solve the ill-posed inverse problem", Remote Sens. Environ. 84, 1-15 (2002) [doi:10.1016/S00344257(02)00035-4].

[32] Y. Knyazikhin, J. V. Martonchik, D. J. Diner, R. B. Myneni, M. Verstraete, B. Pinty, and N. Gobron, "Estimation of vegetation canopy leaf area index and fraction of absorbed photosynthetically active radiation from atmosphere-corrected MISR data", J. Geophys. Res. 103 (D24), 32239-32256 (1998) [doi:10.1029/98JD02461].

[33] M. Weiss, F. Baret, R. B. Myneni, A. Pragnère, and Y. Knyazikhin, "Investigation of a model inversion technique to estimate canopy biophysical variables from spectral and directional reflectance data", Agronomie 20, 3-22 (2000) [doi:10.1051/agro:2000105].

[34]C. Bacour, F. Baret, D. Beal, M. Weiss, and K. Pavageau, "Neural network estimation of LAI, fAPAR, fCover and LAIxCab, from top of canopy MERIS reflectance data: Principles and validation", Remote Sens. Environ. 105, 313-325 (2006) [doi:10.1016/j rse.2006.07.014].

[35] H. Fang, and S. Liang, "A hybrid inversion method for mapping leaf area index from MODIS data: experiments and application to broadleaf and needleleaf canopies", Remote Sens. Environ. 94, 405-424 (2005) [doi:10.1016/j.rse.2004.11.001].

[36]M. Weiss, and F. Baret, "Evaluation of canopy biophysical variable retrieval performances from the accumulation of large swath satellite data", Remote Sens. Environ. 70, 293-306 (1999) [doi:10.1016/S0034-4257(99)00045-0].

[37] B. Koetz, F. Baret, H. Poilve, and J. Hill, "Use of coupled canopy structure dynamic and radiative transfer models to estimate biophysical canopy characteristics", Remote Sens. Environ. 95, 115-124 (2005) [doi:10.1016/j.rse.2004.11.017].

[38] Y. Qu, J. Wang, H. Wan, X. Li, and G. Zhou, "A Bayesian network algorithm for retrieving the characterization of land surface vegetation" Remote Sens. Environ. 112, 613-622 (2008) [doi:10.1016/j.rse.2007.03.031].

[39] C. Atzberger, "Object-based retrieval of biophysical canopy variables using artificial neural nets and radiative transfer models", Remote Sens. Environ. 93, 53-67 (2004) [doi:10.1016/j.rse.2004.06.016]. 
[40] R. Houborg, and E. Boegh, "Mapping leaf chlorophyll and leaf area index using inverse and forward canopy reflectance modeling and SPOT reflectance data", Remote Sens. Environ. 112, 186-202 (2008) [doi:10.1016/j.rse.2007.04.012].

[41]N. H. Broge, and E. Leblanc, "Comparing prediction power and stability of broadband and hyperspectral vegetation indices for estimation of green leaf area index and canopy chlorophyll density", Remote Sens. Environ. 76, 156-172 (2001) [doi:10.1016/S0034-4257(00)00197-8].

[42]D. Haboudane, J. R. Miller, N. Tremblay, P. J. Zarco-Tejada, and L. Dextraze, "Integrated narrow-band vegetation indices for prediction of crop chlorophyll content for application to precision agriculture", Remote Sens. Environ. 81, 416-426 (2002) [doi:10.1016/S0034-4257(02)00018-4].

[43] G. Le Maire, C. Francois, and E. Dufrene, "Towards universal broad leaf chlorophyll indices using PROSPECT simulated database and hyperspectral reflectance measurements", Remote Sens. Environ. 89, 1-28 (2004) [doi:10.1016/j.rse.2003.09.004].

[44] A. Huete, K. Didan, T. Miura, E. P. Rodriguez, X. Gao, and L. G. Ferreira, "Overview of the radiometric and biophysical performance of the MODIS vegetation indices", Remote Sens. Environ. 83, 195-213 (2002) [doi:10.1016/S00344257(02)00096-2].

[45] A. A. Gitelson, A. Viña, V. Ciganda, and D. C. Rundquist, "Remote estimation of canopy chlorophyll content in crops", Geophys. Res. Lett. 32, L08403, (2005) [doi:10.1029/2005GL022688].

[46] S. Y. Kotchenova, E. F. Vermote, R. Matarrese, and F. J. Klemm Jr., "Validation of a vector version of the $6 \mathrm{~S}$ radiative transfer code for atmospheric correction of satellite data. Part I: Path Radiance", Appl. Optics 45,6726-6774 (2006) [doi:10.1364/AO.45.006762].

[47] E. F. Vermote, N. Z. El Saleous, C. O. Justice, Y. J. Kaufman, J. Privette, L. Remer, J.-C. Roger, and D. Tanré, "Atmospheric correction of visible to middle infrared EOS-MODIS data over land surface, background, operational algorithm and validation", J. Geophys. Res. 102, 17131-17141 (1997) [doi:10.1029/97JD00201].

[48] A. Kuusk, "A Markov chain model of canopy reflectance”, Agric. For. Meteorol. 76, 221-236 (1995) [doi:10.1016/0168-1923(94)02216-7].

[49] A. Kuusk, "A two-layer canopy reflectance model", J. Quant. Spectrosc. Ra. 71, 1-9 (2001) [doi:10.1016/S0022-4073(01)00007-3].

[50]D. S. Kimes, and P. J. Sellers, "Inferring hemispherical reflectance of the earth's surface for global energy budgets from remotely sensed nadir of directional radiance values", Remote Sens. Environ. 18, 205-223 (1985) [doi:10.1016/00344257(85)90058-6].

[51] C. Bacour, S. Jacquemoud, M. Leroy, O. Hauteceur, M. Weiss, L. Prévot, N. Bruguier, and $\mathrm{H}$. Chauki, "Reliability of the estimation of vegetation characteristics by inversion of three canopy reflectance models on airborne POLDER data", Agronomie 22, 555-565 (2002) [doi:10.1051/agro:2002039].

[52]H. Fang, S. Liang, and A. Kuusk, "Retrieving leaf area index using a genetic algorithm with a canopy radiative transfer model", Remote Sens. Environ. 85, 257270 (2003) [doi:10.1016/S0034-4257(03)00005-1].

[53]F. Baret, and T. Fourty, "Radiometric estimates of nitrogen status in leaves and canopies", in Diagnosis of the Nitrogen Status in Crops, G. Lemaire, Ed., pp. 201227, Springer, Berlin, Germany (1997).

[54] S. Jacquemoud, and F. Baret, "PROSPECT: A model of leaf optical properties spectra", Remote Sens. Environ. 34, 75-91 (1990) [doi:10.1016/0034$\underline{4257(90) 90100-Z] .}$ 
[55]E. J. Botha, B. Leblon, B. Zebarth, and J. Watmough, "Non-destructive estimation of potato leaf chlorophyll from canopy hyperspectral reflectance using the inverted PROSAIL model", Int. J. Appl. Earth Obs. Geoinf. 9, 360-374 (2007) [doi:10.1016/j.jag.2006.11.003].

[56]B. Hosgood, S. Jacquemoud, G. Andreoli, J. Verdebout, G. Pedrini, and G. Schmuck, "Leaf Optical Properties Experiment 93 (LOPEX93)", European Commission, Joint Research Centre, Institute for Remote Sensing Applications, Report EUR 16095 EN (1995).

[57] Q. Zhang, X. Xiao, B. Braswell, E. Linder, S. Ollinger, M.-L. Smith, J. P. Jenkins, F. Baret, A. D. Richardson, B. Moore III, and R. Minocha, "Characterization of seasonal variation of forest canopy in a temperate deciduous broadleaf forest, using daily MODIS data", Remote Sens. Environ. 105, 189-203 (2006) [doi:10.1016/j.rse.2006.06.013].

[58] J. D. Barnes, L. Balaguer, E. Manrique, S. Elvira, and A. W. Davison, “A reappraisal of the use of DMSO for the extraction and determination of chlorophyll $\mathrm{a}$ and $\mathrm{b}$ in lichens and higher plants", Environ. Exp. Bot. 32, 85-100 (1992) [doi:10.1016/00988472(92)90034-Y].

[59] J. Markwell, J. C. Ostermann, and J. L. Mitchell, "Calibration of the Minolta SPAD502 leaf chlorophyll meter", Photosynth. Res. 46, 467- 472 (1995) [doi:10.1007/BF00032301].

[60] J. Uddling, J. Gelang-Alfredsson, K. Piikki, and H. Pleijel, "Evaluating the relationship between leaf chlorophyll concentration and SPAD-502 chlorophyll meter readings", Photosynth. Res. 91, 37-46 (2007) [doi:10.1007/s11120-006-90775].

[61] A. D. Richardson, S. P. Duigan, and G. P. Berlyn, "An evaluation of noninvasive methods to estimate foliar chlorophyll content", New Phytol. 153, 185-194 (2002) [doi:10.1046/j.0028-646X.2001.00289.x].

[62] B. N. Holben, T. F. Eck, I. Slutsker, D. Tanre, J. P. Buis, A. Setzer, E. Vermote, J. A. Reagan, Y. Kaufman, T. Nakajima, F. Lavenu, I. Jankowiak, and A. Smirnov, "AERONET- a federated instrument network and data archive for aerosol characterization", Remote Sens. Environ. 66, 1-16 (1998) [doi:10.1016/S00344257(98)00031-5].

[63] J. T. Tou, and R. C. Gonzalez, Pattern recognition principles, Addison-Wesley, Reading, Massachusetts (1974).

[64]D. A. Miller, and R. A. White, "A Conterminous United States Multilayer Soil Characteristics Dataset for Regional Climate and Hydrology Modeling", Earth $\begin{array}{llll}\text { Interact. } & \mathbf{2}, & 1-26 & \text { (1998) [doi:10.1175/1087- }\end{array}$ 3562(1998)002<0001:ACUSMS $>2.3 . \mathrm{CO} ; 2]$.

[65] H. Fang, and S. Liang, "Retrieving leaf area index with a neural network method: Simulation and validation", IEEE T. Geosci. Remote 41, 2052- 2062 (2003) [doi:10.1109/TGRS.2003.813493].

[66] A. Kuusk, "Monitoring of vegetation parameters on large areas by the inversion of a canopy reflectance model", Int. J. Remote Sens. 19, 2893-2905 (1998) [doi:10.1080/014311698214334].

[67] R. Darvishzadeh, A. Skidmore, M. Schlerf, and C. Atzberger, "Inversion of a radiative transfer model for estimating vegetation LAI and chlorophyll in a heterogeneous grassland", Remote Sens. Environ. 112, 2592-2604 (2008) [doi:10.1016/j.rse.2007.12.003].

[68] D. Haboudane, J. R. Miller, E. Pattey, P. J. Zarco-Tejada, and I. B. Strachan, "Hyperspectral vegetation indices and novel algorithms for predicting green LAI of crop canopies: Modeling and validation in the context of precision agriculture", Remote Sens. Environ. 90, 337-352 (2004) [doi:10.1016/j.rse.2003.12.013]. 
[69] V. Demarez, S. Duthoit, F. Baret, M. Weiss, and G. Dedieu, "Estimation of leaf area and clumping indexes of crops with hemispherical photographs", Agric. For. Meteorol. 148, 644-655 (2008) [doi:10.1016/j.agrformet.2007.11.015].

[70] M. C. Anderson, J. M. Norman, W. P. Kustas, F. Li, J. H. Prueger, and J. M. Mecikalski, "Effects of vegetation clumping on two-source model estimates of surface energy fluxes from an agricultural landscape during SMACEX", $J$. Hydrometeorol. 6, 892-909 (2005) [doi:10.1175/JHM465.1].

[71] S. Garrigues, N. V. Shabanov, K. Swanson, J. T. Morisette, F. Baret, and R. B. Myneni, "Intercomparison and sensitivity analysis of Leaf Area Index retrievals from LAI-2000, AccuPAR, and digital hemispherical photography over croplands", Agric. For. Meteorol. 148, 1193-1209 (2008) [doi:10.1016/j.agrformet.2008.02.014].

[72] P. J. Zarco-Tejada, C. A. Rueda, and S. L. Ustin, "Water content estimation in vegetation with MODIS reflectance data and model inversion methods", Remote Sens. Environ. 85, 109-124 (2003) [doi:10.1016/S0034-4257(02)00197-9].

[73] A. A. Gitelson, Y. J.Kaufman, and M. N. Merzlyak, "Use of a Green Channel in Remote Sensing of Global Vegetation from EOS-MODIS", Remote Sens. Environ. 58, 289-298 (1996) [doi:10.1016/S0034-4257(96)00072-7].

[74] G. Le Maire, C. Francois, K. Soudani, D. Berveiller, J.-Y. Pontailler, N. Breda, H. Genet, H. Davi, and E. Dufrene, "Calibration and validation of hyperspectral indices for the estimation of broadleaved forest leaf chlorophyll content, leaf mass per area, leaf area index and leaf canopy biomass", Remote Sens. Environ. 112, 3846-3864 (2008) [doi:10.1016/j rse.2008.06.005].

Rasmus Houborg is now at NASA Goddard Space Flight Center/Earth System Science Interdisciplinary Center, University of Maryland. Up to recently he was a Research Physical Scientist with the USDA-ARS Hydrology and Remote Sensing Laboratory. He received his BS, MS and PhD degrees in Physical Geography from the University of Copenhagen in 1999, 2002, and 2006, respectively.

Martha C. Anderson is a Research Physical Scientist with the USDA-ARS Hydrology and Remote Sensing Laboratory. She received her BA in Physics from Carleton College in 1987 and a PhD degree in Astrophysics from the University of Minnesota in 1993. She was a research scientist at the University of Wisconsin. 